\title{
Trivium
}

Revue franco-allemande de sciences humaines et sociales - Deutsch-französische Zeitschrift für Geistesund Sozialwissenschaften

1 | 2008

"Iconic Turn » et réflexion sociétale

\section{Das ornamentale Pathos nach Piero und Antonio Pollaiuolo}

\section{Bertrand Prévost}

Traducteur : Bernd Schwibs

\section{(2) OpenEdition}

Journals

Édition électronique

URL : http://journals.openedition.org/trivium/333

DOI : $10.4000 /$ trivium.333

ISSN : 1963-1820

Éditeur

Les éditions de la Maison des sciences de l'Homme

Référence électronique

Bertrand Prévost, « Das ornamentale Pathos nach Piero und Antonio Pollaiuolo », Trivium [Online], 1 ।

2008, online erschienen am 08 April 2008, abgerufen am 10 Dezember 2020. URL : http://

journals.openedition.org/trivium/333; DOI : https://doi.org/10.4000/trivium.333

Ce document a été généré automatiquement le 10 décembre 2020.

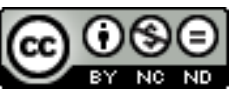

Les contenus des la revue Trivium sont mis à disposition selon les termes de la Licence Creative Commons Attribution - Pas d'Utilisation Commerciale - Pas de Modification 4.0 International. 


\title{
Das ornamentale Pathos nach Piero und Antonio Pollaiuolo
}

\author{
Bertrand Prévost \\ Traduction : Bernd Schwibs
}

\section{NOTE DE L'ÉDITEUR}

Aus urheberrechtlichen Gründen ist es uns leider nicht möglich, alle im Originalartikel enthaltenen Abbildungen an dieser Stelle zu reproduzieren. Der Übersicht halber wurde die Gesamtheit der Bildverweise im Text jedoch beibehalten, Verweise auf fehlende Abbildungen sind fett dargestellt. Der interessierte Leser wird gebeten, die Originalausgabe heranzuziehen.

Ein besonderer Dank gilt dem Ministero per i Beni e le Attività Culturali in Florenz und dem Walters Art Museum in Baltimore für die kostenlose Bereitstellung einiger Abbildungen. Ein weiterer Dank gilt dem Verlag Actes Sud, bei dem der Text im Original erschienen ist, für die freundliche Genehmigung zur Übersetzung.

1 Aby Warburg hatte die Pathosformeln eigentlich »erfunden«, um namentlich dem Rechnung zu tragen, was er bei Pollaiuolo als aus »dämonisch finsteren Zügen der Antike« erwachsenes "Pathos « erkannte. ${ }^{1}$ Wie wir wissen, wollte der deutsche Kunsthistoriker darin nicht nur ein aus spezifisch künstlerischer Tätigkeit oder bloßer Beschäftigung mit der Form entsprungenes, rein formales Element sehen. Vielmehr brachte er es in Zusammenhang mit einem bestimmten Lebensgefühl oder »Kontakt mit der Zeit«, dessen einzigartige Intensivierung in der florentinischen Kunst des Quattrocento er analysierte. Freilich wird mit der Verwendung des »Pathos«-Begriffs ein bestimmtes theoretisches Risiko eingegangen, das auch in der wissenschaftlichen Rede leicht auszumachen ist: dass Pathos sehr schnell zu pathetischer Affektiertheit gerät. Theoretisch wäre die Gefahr darin zu verorten, dass eine - durchaus zu Recht als "Pathos« bezeichenbare - Intensität auf eine in ihrer Form und Bedeutung besonders sinnfällige Darstellung verkürzt wird: die Falle einer spektakulären Evidenz- bei Pollaiuolo also die so sichtbar erregten, so offenkundig affizierten Körper. ${ }^{2}$ Will man 
diese Klippe umschiffen, muß das zentrale Problem aufgeworfen werden: Wie lassen sich Intensität und Form verbinden, wenn davon ausgegangen wird, dass Intensität nicht a priori in einer Darstellung gegeben ist? Welche Beziehungen unterhält das Intensive mit dem Ausgedehnten, also dem Räumlichen? Wie lassen sich Ausdruck und Formel ohne den idealen Beistand einer Synthese zusammenbringen? Woraus oder vielmehr auf welche Weise gewinnen in den Bildern Pollaiuolos die Gebärden ihre Intensität? Letztlich geht es nur um eine Frage der Eigenart: Warum ist es triftig, die Gebärden ins Zentrum der Pollaiuolonischen Erfindung zu stellen? Warum erhalten die Gebärden bei Pollaiuolo den Status eines künstlerischen Problems?

\section{Expressive Merkmale}

\section{Merkmale von Manie, Merkmale von Gesichtshaftigkeit}

Abb. 63

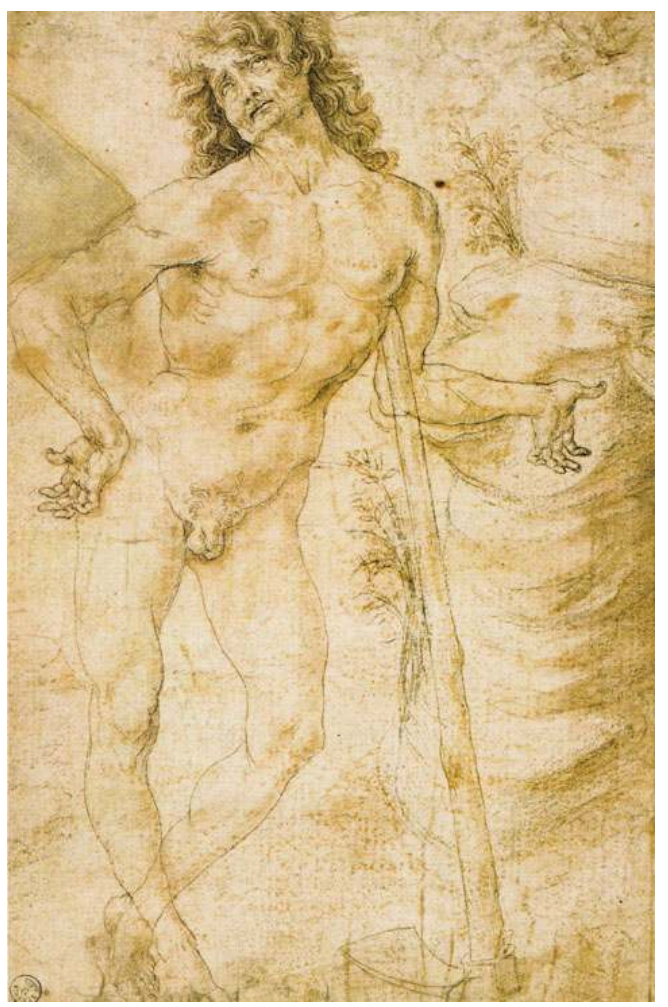

Antonio Pollaiuolo: Adam, ca. 1470.

(C) Ministero per i Beni e le Attività Culturali, Polo Museale Fiorentino

Ein Weg zur Klärung dieser Fragen könnte darin bestehen, nochmals in Augenschein zu nehmen, was bestimmte Kunsthistoriker, darunter nicht zuletzt Warburg selbst, ganz $\mathrm{zu}$ Recht als den »Manierismus« Pollaiuolos bezeichnet haben. ${ }^{3}$ Was ist davon zu halten? Richtig ist, dass »etwas geschieht«, dass in den Bildern Pollaiuolos viel Geschäftigkeit herrscht, so als wären die Körper gleichsam besessen und in Beschlag genommen von einem gebieterischen Bedürfnis nach Aktivität und Bewegung: Körper, die nicht stillhalten können, die im Stillstand und zugleich doch in Bewegung sind. Im Grund verweist die übersteigerte Betriebsamkeit bei Pollaiuolo immer auf einen 
bestimmten Einsatz der Hand, auf eine Handhabung, auf ein in seinem Exzeß sonderbares Hantieren. Fortwährend wird da berührt, ergriffen, gepackt, kurzum: mit der Hand gewirkt. ${ }^{4}$ Wie schmal der Grat zwischen Manie und Manierismus ist, zeigt eine prächtige Zeichnung, auf der Adam und Eva abgebildet sind sowie der Krampf, der die Hände des Mannes erfasst hat und die Finger der Hand rechts sich krümmen und die Hand links in einem anatomisch unwahrscheinlichen Winkel nach unten ausschlagen läßt, während sein Kopf nach links abgewandt ist (Abb. 63). Mehr noch, das sonderbare Gebaren der Hände findet sich gleichsam allegorisiert im ikonographischen Thema dieser beiden Abbildungen: weder >Adam und Eva im Paradies« noch `Adam und Eva aus dem Paradies vertrieben`, sondern `Adam und Eva außerhalb des Paradieses`, dazu verdammt, zu arbeiten, Feldarbeit (Adam mit der Harke) wie Hausarbeit zu verrichten (Eva mit dem Spinnrocken). Bereits hervorgehoben wurde, dass Pollaiuolos bevorzugte Helden - Herkules und David - sehr häufig Allegorien für die vita activa darstellen, also für das arbeitsame Leben im Kontakt mit der Welt. Nun wird in dieser Abbildung Adams die Arbeit zwar thematisiert, aber es ist doch bezeichnend, dass Adam die Harke nicht fest mit den Händen gepackt hat, sondern dass er sie locker in der Achselhöhle hält. Hier wird von Manier gesprochen, um die Expressivität eines Gebärdenmerkmals zu bezeichnen; und von Manierismus, um die Art und Weise zu kennzeichnen, in der diese Merkmale für sich selbst arbeiten müssen, ohne auf ein Hilfsmittel oder, allgemeiner, auf eine organische oder instrumentelle Funktion zweckhaft bezogen zu sein. Auf einer anderen Zeichnung, einer Skizze zu Johannes dem Täufer (Abb. 65), scheint die Intensität ebenso in die Gestik, die Bewegung der Hände eingegangen zu sein wie in die Verbissenheit, mit der die Hand des Künstlers das Studium der Hand betreibt: Gebärden der Affektion (die Hand auf der Brust), Gebärden des Greifens (die das Spruchband krampfhaft haltende Hand, eine weitere Hand am Bleistift - Palimpsest? - läßt sich erahnen), nicht weniger als viermal neben der Gestalt nervös skizziert. Die Florentiner Kunst des Quattrocento, zumal die Zeichnung, wird diese Morphologie der Handgeste ausführlich bearbeiten.

3 Auf diesen sonderbaren Manierismus ist ebenfalls die ausgeprägte Aufmerksamkeit zurückzuführen, mit der die Bilder Pollaiuolos das Mienenspiel bedenken, als ob die Fülle an Bewegungen - sei es exzessive Gestikulation oder winzige Manie - sich auf den Gesichtern verdichten würde, als ob eine emphatische Gebärdensprache sich auch an einem Kopf, einer Physiognomie konzentriert entfalten könnte. Binswanger verwies sehr prägnant in seiner Studie über den Manierismus sowohl auf dessen "gezüchtete Strenge«, »Geist des Korsetts« und »Etikette«, als auch auf das Preziöse und »TänzelndSpielerische«. ${ }^{5}$ Es reicht nicht aus, auf das »realistische«, nicht idealisierte Äußere der Gesichter Pollaiuolos abzuheben, um dies dann auch noch gleich mit dem einflussreichen »Realismus« der Schulen des Nordens in Zusammenhang zu bringen: die von Falten und Runzeln zerfurchten, von schütteren Bärten, Spitz- und Schnurrbärten durchzogenen oder von struppigem Haar überwucherten, knorrigen und gedunsenen Gesichter (Abb. 24, 18, 17, 54 usw.). Auch deren eigentlich dynamischer, also mimischer Aspekt ist hervorzuheben: all diese grimassierenden Gesichter, all diese die Zähne fletschenden Münder, verbissen in der Anstrengung des Kampfes, weit aufgerissen, um einen Kampfschrei oder einen unsäglichen Schmerzensschrei auszustoßen; all diese gerunzelten Augenbrauen, die sich senken, sich heben, all diese verdrehten Augen; oder auch, was in der Renaissance-Malerei nur selten erscheint, das Lächeln (sogar Lachen), das die Gesichtszüge eines der Tänzer der Villa Gallina aufhellt (Abb. 66). Eine einzige Arbeit des Faltens, Runzelns, Verdrehens: 
allesamt Differenz setzende Verfahren, die das Gesicht auseinandernehmen, indem sie den Intensitätslinien folgen, die sich ihm zu entziehen suchen.

\section{Eine Eigenart}

Abb. 67

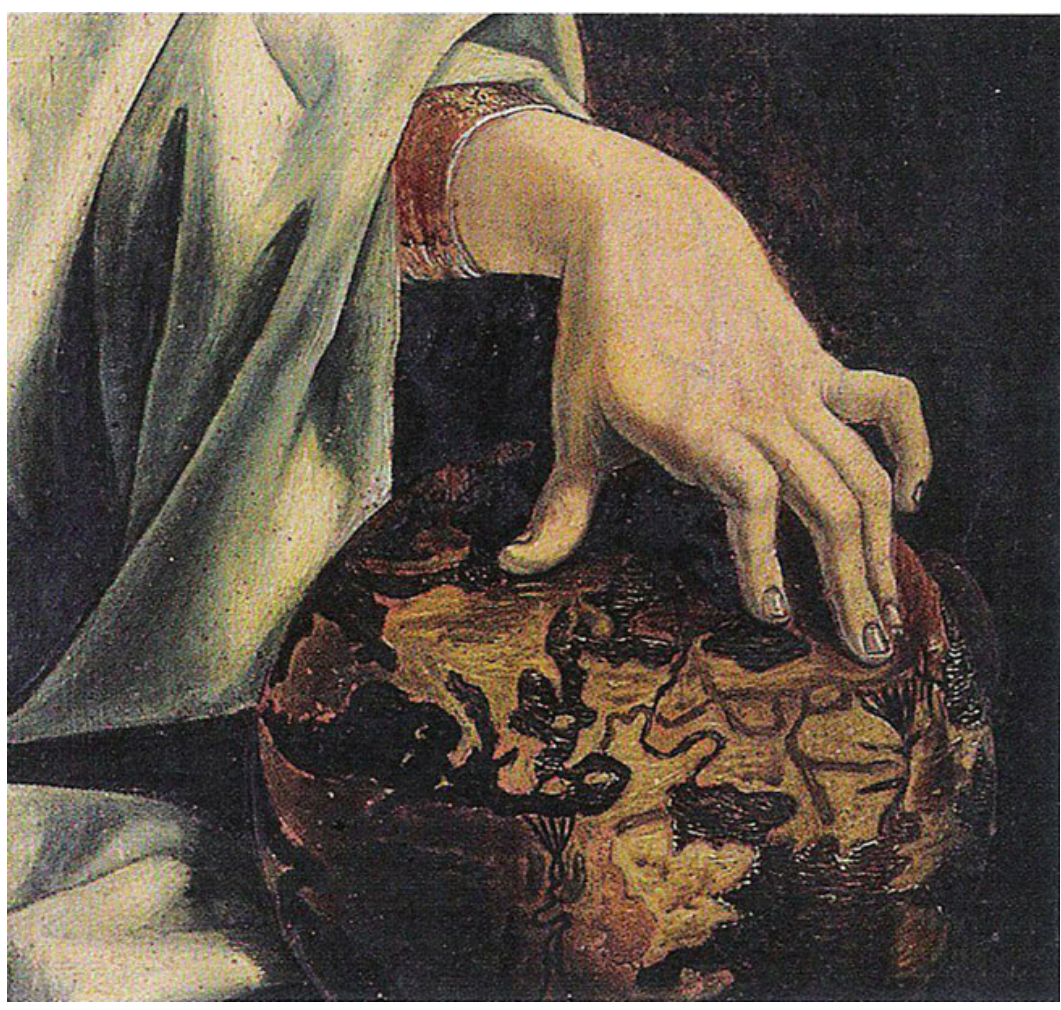

Antonio und Piero Pollaiuolo: Allegorie der Gerechtigkeit, Ausschnitt, 1469-1470.

(C) Ministero per i Beni e le Attività Culturali, Polo Museale Fiorentino

Alle diese winzigen Bewegungen scheinen um ein stets wiederkehrendes Motiv zu kreisen, das sich wie ein morphologisches Anziehungsfeld verhält: das Abspreizen des kleinen Fingers, der »abstehende« kleine Finger. Eine Gebärde an der Grenze zur NichtGebärde, eine winzig kleine Bewegung, lächerlich fast oder komisch, vom bloßen Tic zur irrsten Deformation reichend. Das Motiv verblüfft nicht zuletzt deshalb, weil es im Werk Pollaiuolos immer wieder auftaucht, ohne dass sich Phasen des Auftretens oder Momente des Verschwindens in der Chronologie der Werke wirklich unterscheiden ließen. Man stößt darauf bei mindestens zwei der Allegorien für die Zunft der Händler (Abb. 67) und an der rechten Hand des hl. Eustachius in der Grabkapelle des Kardinals von Portugal in der Basilika San Miniato al Monte (Abb. 68); die gleiche Bewegung bemächtigt sich auch der einen Hand Apollos auf der Holztafel in der National Gallery (Abb. 42); am augenscheinlichsten aber ist dieses Motiv wohl im Berliner David, da es sich an beiden Händen des Helden zeigt (Abb. 69).

Die Kunstgeschichte war für das beharrlich auftretende Motiv des gekrümmten, abgespreizten kleinen Fingers bei Pollaiuolo durchaus nicht unempfänglich. Doch wenn sie sich dafür interessierte, dann immer nur, um es auf Identitätsformen zu reduzieren. Zunächst dergestalt, dass sie darin ein zentrales Identifizierungsmerkmal für die 
Zuschreibung eines Pollaiuolonischen Werks sah. Wir verweisen hier auf die berühmte Morelli-Methode, der zufolge "nach dem Antlitze die Hand der vergeistigste, charakteristischste Theil des menschlichen Körpers sei«.6 (Abb.70). Aber diese expressive Geste galt für den Kenner lediglich als Hinweis auf ein Sujet, eine Identität. Die in den Bildern Pollaiuolos wirksamen Manie-Merkmale verwandelten sich so in die Manie des Künstlers selbst, die Eigenart eines Gebärden-Zeichens in eine Signatur Pollaiuolos. Gewiß erbrachte das Zuschreibungsverfahren Ergebnisse, allerdings nurgemäß unzureichend gestellter historischer und theoretischer Probleme.

Abb. 70

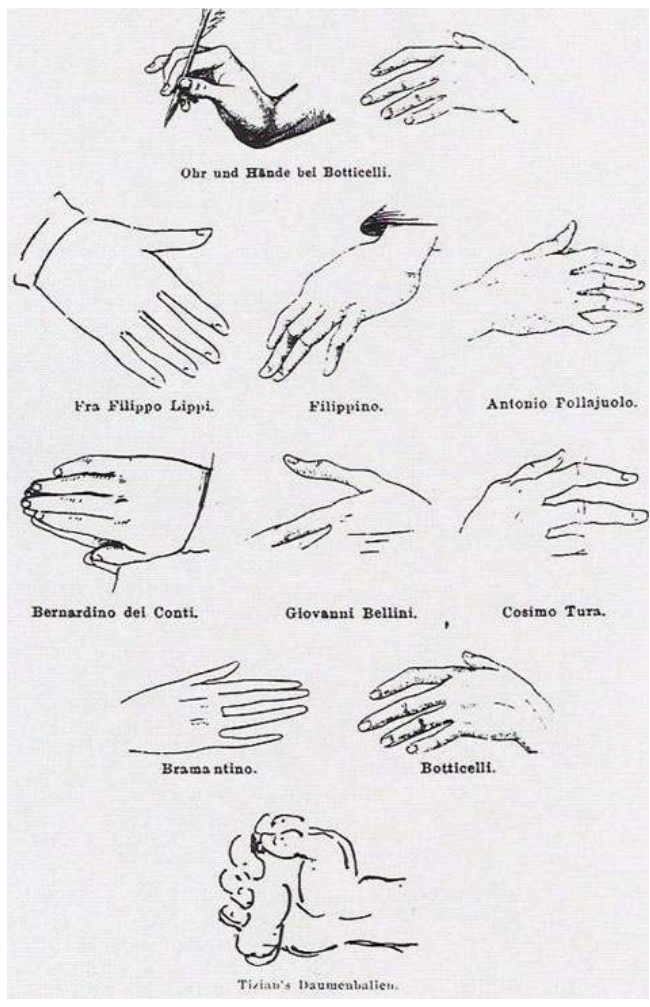

»Den Künstler an der Form der Hände erkennen«, Bildtafel aus Giovanni Morelli, De la peinture italienne (1890).

Ein weiteres Verfahren, das Pollaiuolonische Motiv nicht zu betrachten, besteht darin, es ohne Umschweife in die Schublade der formalen Stereotype zu stecken, mit dem vordergründigen Argument, es sei lediglich eine den visuellen Künsten des Quattrocento insgesamt vertraute Konvention. ${ }^{7}$ Zweifellos weisen die ferraresischen und florentinischen Gemälde des Quattrocento - um nur diese zu erwähnen - eine Fülle von abgespreizten kleinen Fingern auf. Zudem scheint das Motiv der Hand, die sich mit Daumen und Zeigefinger sachte an einem Gürtel festhält, wobei der kleine Finger abgespreizt ist (wie man es bei David und dem hl. Eustachius der Grabkapelle des Kardinals von Portugal findet [Abb. 68, 69]), tatsächlich den Wert eines spezifischen Stereotyps der florentinischen Malerei der zweiten Hälfte des Quattrocento, zumindest zwischen 1450 und 1490, anzunehmen. Schon ein rascher Überblick erweist, dass es sich um eine kodifizierte Formel handelt, da man sie sowohl bei den erstrangigen Malern wie Pollaiuolo und Botticelli findet als auch auf anonymen Kupferstichen und kunsthandwerklichen Darstellungen. Doch darin lediglich ein formales Stereotyp zu sehen gelingt nur um den Preis, dass jede konkrete Umsetzung, jeder morphologische 
Kontext eines Motivs ausgeblendet wird, um es einer Idealgeschichte der Formen zuzuschlagen. Damit soll gesagt sein, dass die ganze Arbeit der Bilder Pollaiuolos eben darin besteht, dieses Motiv, wie konventionell auch immer, dadurch $\mathrm{zu}$ einem einzigartigen $\mathrm{zu}$ machen, dass es einem System interner Resonanzen eingefügt wird, das seine ästhetische Relevanz zu unterstreichen und seinen Ausdruck zu intensivieren vermag.

Abb. 69

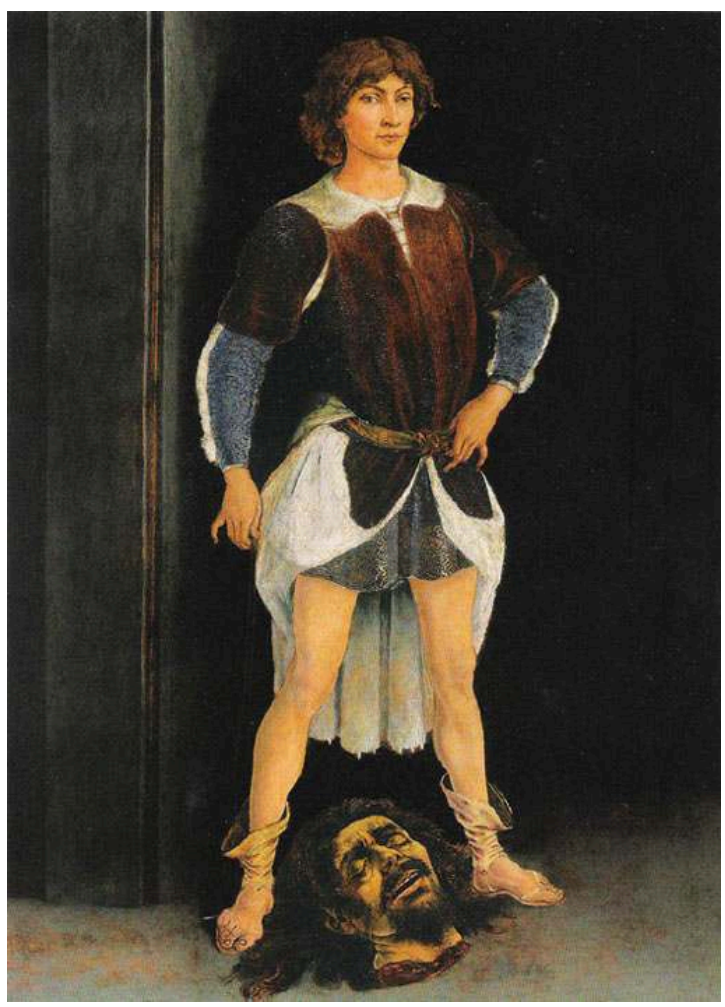

Antonio Pollaiuolo: David, ca. 1470.

Photo (c) RMN, Jörg P. Anders

7 Auch wenn es sich um ein Stereotyp handeln mag, muß doch berücksichtigt werden, dass dieses Stereotyp auf die Spitze getrieben ist, dass seine zwanghafte Wiederholung eine Insistenz anzeigt, die durch ein bloßes Repertoire der Formen nicht erklärt werden kann. Diese Insistenz muß zwangsläufig $\mathrm{zu}$ Ungereimtheiten in der historischen Ordnung der Darstellung führen. In dieser Hinsicht ist der Berliner David (Abb. 69) ausgesprochen interessant, vor allem wegen der Wiederholung des Motivs an beiden Händen: der einen, die den Gürtel, der anderen, die die Schleuder hält. Besteht hier nicht ein Missverhältnis zwischen der delikaten Leichtigkeit der Geste und der Art und Weise, in der der siegreiche Held fest auf dem Boden steht, die Beine weit gespreizt und wie festgerammt in der Erde? Besteht hier nicht eine Spannung zwischen der zwanglosen Gebärde einer Hand, deren Fingerspitzen sich sacht auf einem Gürtel und einer Schnur niederlassen, und der Art und Weise, in der die Gestalt sich aufzwingt was auch durch die geschwellte Brust und den stark herausgedrückten Ellenbogen des linken Arms zum Ausdruck gebracht wird?

8 Vom abgespreizten kleinen Finger bis zu den sonderbaren Handverrenkungen bei Adam (Abb. 63) oder der Allegorie der Gerechtigkeit (Abb. 67): stets ist etwas wie ein manischer 
Zug spürbar, der die Gestik vertreibt und eine Intensitätslinie zeichnet, die mit der organischen und anatomischen Ordnung des Körpers nichts zu schaffen hat. ${ }^{8}$ Denn was der Hand durch die Bewegung des kleinen Fingers abhanden zu kommen droht ist ihre Funktion als Organ: Während ein Organ insoweit an einer bestimmten Ordnung des Körpers teilhat, als es darin eine ganz bestimmte Stelle einnimmt und eine konkrete Funktion erfüllt, ist hier eine Gebärde, die keine Nützlichkeit besitzt und keiner Funktion zuschreibbar ist, die gleichwohl aber durch ihre Bewegung differenziert wird. Weniger eine Gebärde als ein Tic:

»Was ist ein Tic [...]? Es ist der unaufhörliche Kampf zwischen einem Merkmal [der Manie], das der souveränen Organisation des [Organs Hand] entkommen will, und der [Hand] selber, die sich über diesem Merkmal schließt, es wieder integriert und seine Fluchtlinie blockiert, ihm seine Organisation erneut aufzwingt. ' $^{9}$

Beiläufig wird man erkennen, dass der herrschende Diskurs in der Kunstgeschichte, der die Künstler der Renaissance zu den Entdeckern und Apologeten einer Ordnung des Körpers, seines »objektiven", "wissenschaftlichen" anatomischen Aufbaus erhebt, so selbstverständlich nicht ist. Dahinter steht noch immer Vasari, der Pollaiuolo zum ersten Gesetzgeber des menschlichen Körpers kraft seiner anatomischen Praxis erhebt:

"Antonio malte nackte Gestalten auf modernere Art als die Meister vor ihm. Er sezierte viele Leichen, um die menschliche Anatomie kennenzulernen, und war der erste, der den Verlauf der Muskeln zu verfolgen suchte, um sie in seinen Figuren ihrer richtigen Form und Ordnung nach darzustellen. ${ }^{10}$

Nun hören aber gerade die gestischen Merkmale bei Pollaiuolo nicht auf, sich zu verzweigen, an ihrer Spitze eine undenkbare oder unwahrscheinliche Richtung einzuschlagen, so als ob der kleine Finger, ja die ganze Hand gegenüber dem Gesamtkomplex, von dem er bzw. sie organisch abhängig ist, eine motorische Unabhängigkeit gewinnen würde.

\section{Gebärden und Ornament}

\section{Serie, Problem, Stil}

Durch die Mikro-Dimension konnte die Klippe des Bombasts eines gewissen Pathos umschifft werden. Freilich nur zum Schein, da diese Dimension, wie klein auch immer, uns nicht in die ästhetische Tiefe der Gebärden-Serie bei Pollaiuolo einzudringen erlaubt: auch sie hält uns noch gefangen in einem System der - wenn auch weniger spektakulären - Darstellung. Was heißt das? Daß man ein Evidenz-Regime nicht hinter sich läßt, bei dem es noch immer darum geht, Gesten und Körperbewegungen dort (wieder) zu erkennen, wo gerade ein Fluchtvektor, eine Bresche in der Darstellung der Körper wahrzunehmen war. Auf der Ebene der Darstellung zu verbleiben ist auch dann noch unzulässig, wenn nur deren Störungen oder Dysfunktionen herausgefunden, historische und narrative Ungereimtheiten ausgemacht werden sollen; denn diese Darstellungsschicht, es sei nochmals betont, liegt insofern, als sie sich auf sinnhafte Inhalte gründet, immer noch außerhalb dessen, was wir zu rasch als genuinen Raum des visuellen Werks bezeichnet haben, sie umgeht ihn zwangsläufig, verfehlt dessen wesentlichen Kern.

Der Grund dafür ist, dass die Konstruktion einer Serie sich immer am Problem ihrer Einheit, ihrer Kohärenz stößt: diese bleibt zufällig, solange das Entwicklungselement nicht ausgemacht ist, das sie aufrechterhält, das sich in ihr durchhält, obwohl es ihr fremd ist, das in ihr beharrlich fortwirkt und ihr dabei doch heterogen ist. Um die 
intensive Einheit einer Serie zu begründen, reicht es nicht aus, auf ein geschlossenes System interner Resonanzen zu verweisen; man muß zudem die notwendigerweise nicht in die Augen springende, versteckte Zone finden, wo die Serie auf ihr eigenes Äußeres stößt, die Schwelle, wo sie auf die sie singularisierenden heterogenen Serien trifft. Genau darin besteht ja die Gefahr jedes monographischen Ansatzes: dass er die Einheit eines Werks auf eine im vorhinein gegebene Identität verkürzt - die eines Künstlers, einer bestimmten Ikonographie oder einer Formrekurrenz. Sinn gewinnt die Frage der Gebärde durch den Stil Pollaiuolos selbst. Pollaiuolos »Pathos« lässt sich nur über den Stil erfassen. Stil ist nicht, wie häufig angenommen, eine Instanz des Schließens, ist kein Verfahren der Totalisierung, das das Werk eines Künstlers oder irgendein Gesamt von Bildern zum Zwecke der Identifizierung markierte. Vielmehr verweist er auf die Funktion einer Öffnung dieses Ganzen, auf ein Potential des Begegnens, des Zusammentreffens. Stil ist jenes Verfahren, das das geschlossene System interner Resonanzen aus sich heraustreten lässt. Ein problematisches Potential insofern, als es die Serie problematisiert, indem es eine transversale Linie durch sie laufen lässt; ein singularisierendes Potential insofern, als es die Pollaiuolonischen Motive individuiert und darüber hinaus unwiderruflich die Gesamtheit der Bilder Pollaiuolos in ihrer Unterschiedlichkeit festsetzt. Statt also die Eigenart eines abgespreizten kleinen Fingers nach Art Morellis als Identitätsform abzuhaken, wollen wir versuchen, dessen Funktionen der Öffnung, dessen Aspirationsvektoren herauszufinden.

11 Stellen wir direkt folgende Hypothese auf: dieser Vektor strebt nach etwas, was sich mehr oder minder um die Frage des Ornaments dreht; die Schwelle, der Auftakt, Beginn der Gebärden-Serie bei Pollaiuolo ist ornamentaler Natur. Mit anderen Worten: Die Gebärden-Serie bei Pollaiuolo wird einzigartig lediglich im Zusammentreffen mit einer ornamentalen Serie; in Pollaiuolos Stil haben (mindestens) zwei ästhetische Ideen Gestalt gefunden: eine Pathetik des expressiv übersteigerten Körpers zum einen; eine ornamental-abstrakte Ästhetik zum anderen. 
Abb. 71

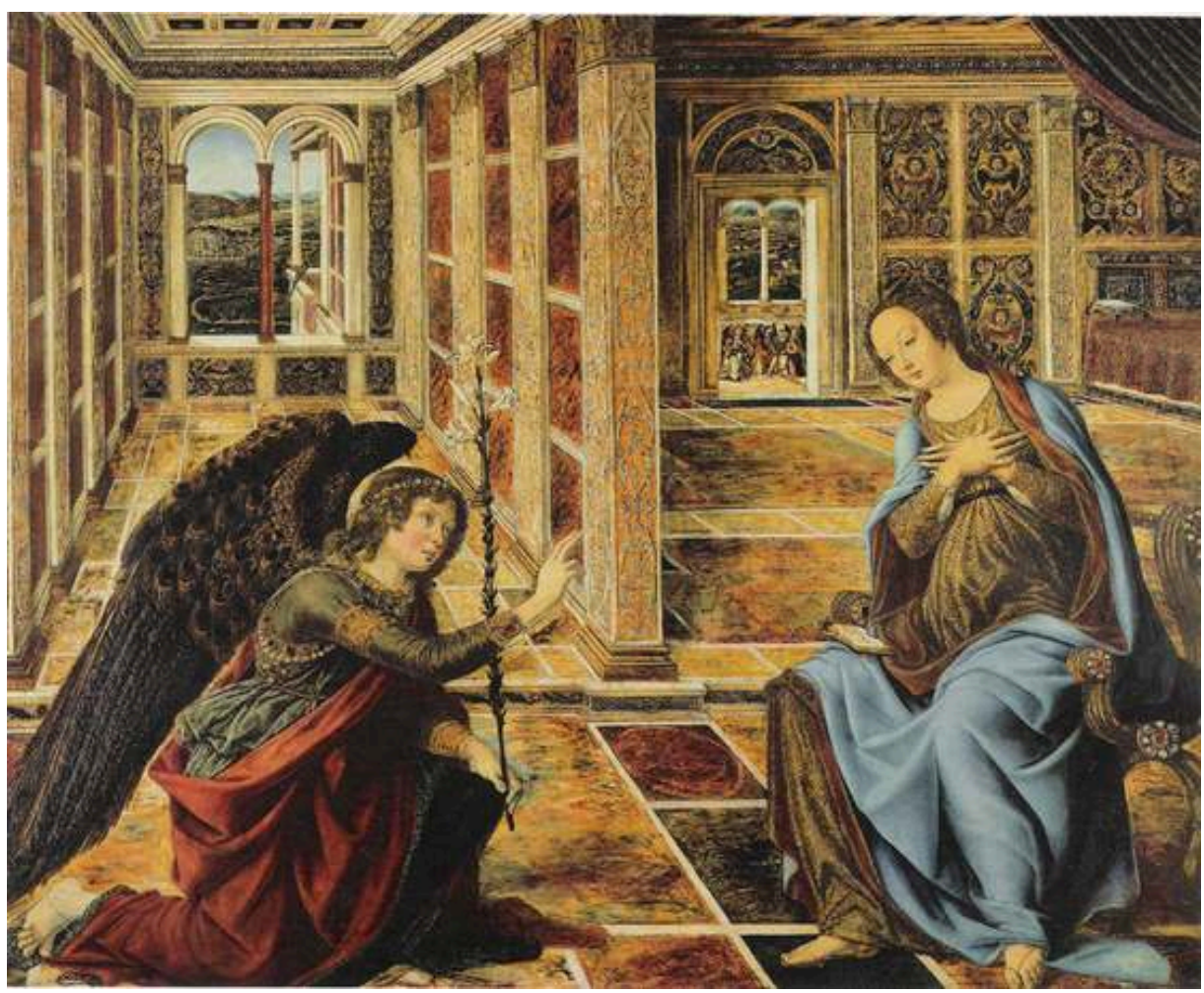

Antonio und Piero Pollaiuolo: Verkündigung, ca. 1470.

Photo @ RMN, Jörg P. Anders

\section{Die ornamentale Serie}

Das Ornamentale und die Gebärde also. Eine auf den ersten Blick insofern paradoxe These, als Ornament und dekorative Elemente in der Regel als nicht-expressiv, unbegründet, affektlos gelten. Gegen diese Annäherung an den ästhetischen Common Sense hatte Warburg mit dem Begriff des »dekorativen Pathos« auf das beharrliche Wirken des Ornamentalen innerhalb der starken Expressivität abgehoben, von der die visuellen Künste der zweiten Hälfte des Quattrocento in Florenz beherrscht sind. Schon in seiner Abhandlung über Botticelli hatte er sich dafür empfänglich gezeigt, dass die Bewegung - exemplarisch bei diesem Künstler - sich nicht so sehr in den berühmten Pathosformeln, also in den bewegten Körpern, den »Formeln gesteigerten körperlichen oder seelischen Ausdrucks«, bekundete, als im »bewegten Beiwerk« und der »äußeren Beweglichkeit der Gestalten «, anders gesagt, in Haar und Gewandung. ${ }^{11}$ Im Unterschied $\mathrm{zu}$ Botticelli bestünde das Kunststück Pollaiuolos darin, ein Ornamental-Werden den Körpern selber und nicht nur ihren Rändern oder ihrer Umgebung einzuschreiben, sie zu skarifizieren. Als würden uns die Bilder Pollaiuolos das Paradox eines OrnamentKörpers und nicht eines ornamental-verzierten Körpers aufdrängen.

Ein rascher Überblick über die Produktionen Pollaiuolos offenbart sofort ein unbestreitbares Interesse für ornamentale Motive. Vergessen wir nicht, dass seine Ausbildung als Goldschmied, wie sie vielen florentinischen Künstlern in der zweiten Hälfte des Jahrhunderts gemeinsam war, ihn für das freie Entwerfen dekorativer Linien und Formen prädisponierte. Auch Vasari unterstreicht seine geniale Geschicklichkeit 
bei der Hervorbringung von »Phantasiestücken «. ${ }^{12}$ Ein Gemälde wie Die Verkündigung (Berlin) mit seiner Fülle an Marmortafeln, seinen Grotesken all'antica, verzierten Pilastern, mit der ostentativen Kostbarkeit der Gewänder, Schmuckstücke und Goldschmiedearbeiten (so dass etwa die Verkündigung des Engels, das berühmte Ave Maria gratia [plena], auf den goldenen Armreifen und Armbinden in Perlenschrift gestickt ist), zeigt einen solchen ornamentalen Reichtum, dass man dies durchaus zu Recht in seiner theoretischen Tiefe erfassen und nicht auf einen bloßen Geschmack an »flämischer Preziosität«, wie sie im Florenz der Jahre 1470-1490 in Mode war, reduzieren darf.

Abb. 72

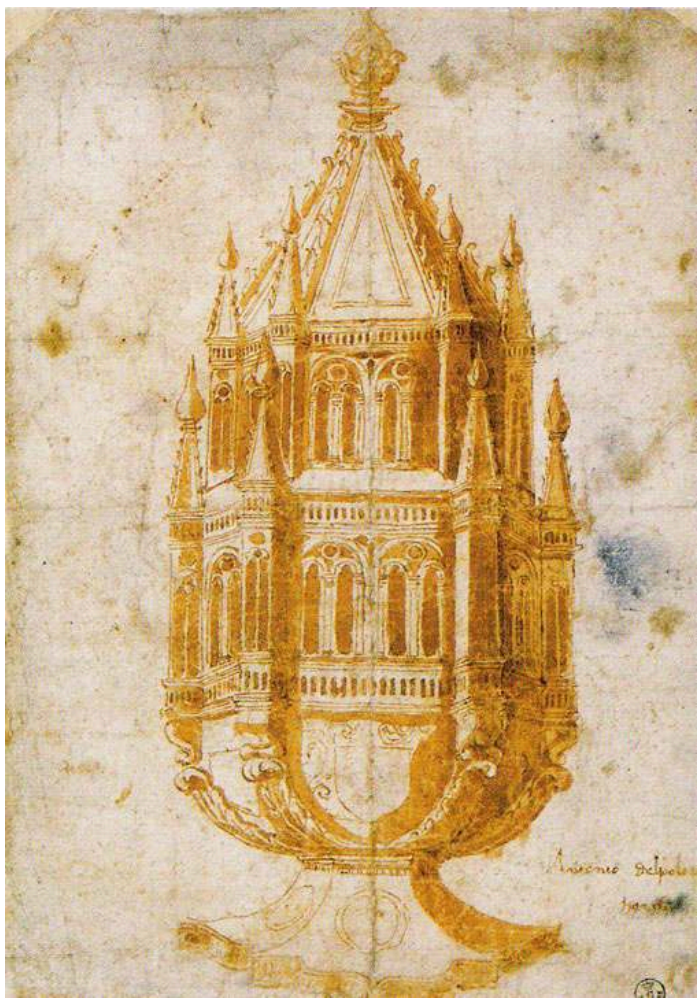

Antonio Pollaiuolo: Skizze eines Weihrauchgefäßes, ca. 1460.

(c) Ministero per i Beni e le Attività Culturali, Polo Museale Fiorentino 
Abb. 74

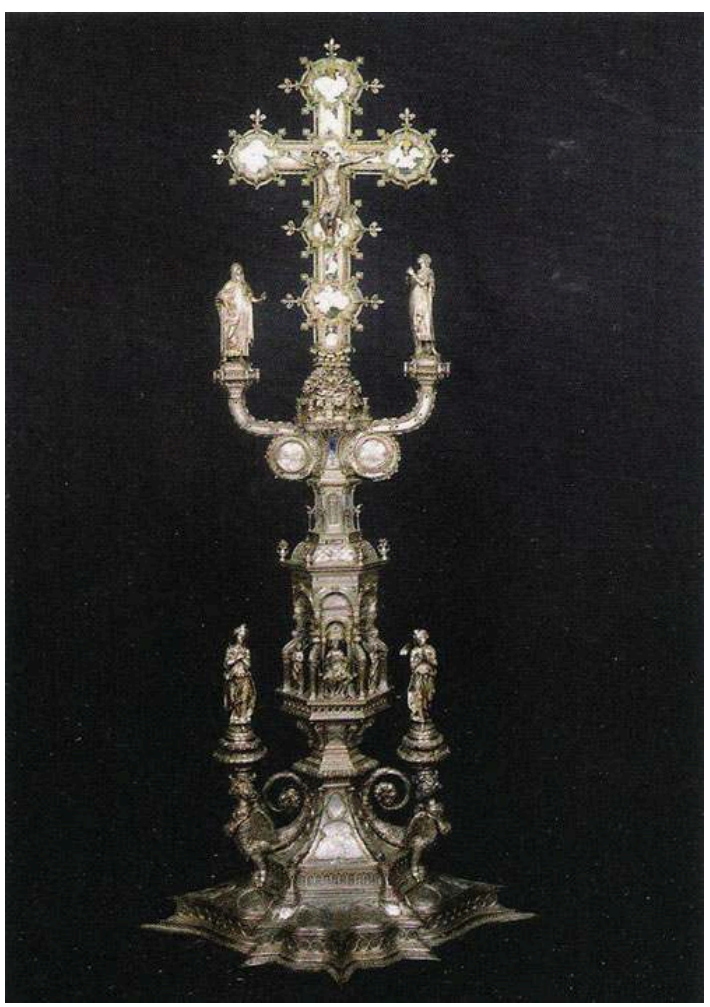

Antonio Pollaiuolo und Betto Betti: Kreuz der Taufkapelle, 1457.

(C) Opera di S. Maria del Fiore, Firenze

Das Ornament scheint bei Pollaiuolo auf zweifache Weise vorhanden zu sein. Der erste Modus, den ich als gotisch oder höfisch oder auch nordisch bezeichnen würde, betrifft vor allem die frühen Werke, wenn es auch falsch wäre, seine Bedeutung für die späteren Werke zu schmälern. ${ }^{13}$ Man darf nicht vergessen, dass im Florenz des Quattrocento das Gotische beileibe noch nicht am Ende war und eine ganze Reihe entsprechender Motive weiterhin in Blüte stand. Das Goldschmiedewesen an sich bildete einen Idealboden für den »internationalen Stil« und das Vokabular des spätgotischen Einfallsreichtums. Beispielhaft die Skizze eines Weihrauchgefäßes (Abb. 72) mit seinen Turmspitzen, seinen züngelnden Flammen und gekräuselten Schleifen ${ }^{14}$, oder auch das erste dokumentierte Werk Pollaiuolos, das wir besitzen: das für den Hauptaltar der Kathedrale von Florenz entworfene große Silberkreuz (Abb. 74). ${ }^{15}$ Die Sockelarbeit (Pollaiuolo hat sich lediglich um den unteren Teil des Kreuzes gekümmert, der dem früher entstandenen eigentlichen Kreuz hinzugefügt wurde) belegt eine ungeheure ornamentale Fülle an monströsen und schimärischen Formen. $\mathrm{Zu}$ erwähnen wäre auch das ins Einzelne gehende Interesse für gemalte Goldschmiedeund Schmuckarbeiten (Abb.71) oder auch für die Verzierungen auf den kostbaren Brokatstoffen (Abb. 68). Der zweite ornamentale Modus wäre demgegenüber mehr klassisch, all'antica. Die Bilder Pollaiuolos wimmeln von Palmetten, Akanthusblättern, Rankenornamenten und extravaganten Chimären (Abb.71). Die florentinischen Künstler haben nicht auf die Entdeckung der Domus Aurea und ihrer Grotesken ganz zu Anfang des 16.Jahrhunderts gewartet, um sich an den Freuden dekorativer "Überfrachtung" und der Erzeugung phantasmagorischer Formen zu ergötzen. ${ }^{16}$ Man muß nur einmal die ornamentale Extravaganz und Überspitztheit betrachten, die z.B. 
die üppig sprießenden Akanthusblätter zu Füßen der Grabmäler von Giovanni und Piero de' Medici in San Lorenzo kennzeichnen (Abb. 73).

\section{Für eine ornamentale Pathetik}

\section{Die ornamentale Morphologie der Gebärden}

15 Zwischen Gebärde und Ornament besteht eine natürliche Affinität, eine Konaturalität. Auf körperlicher oder anatomischer Ebene sind es Gelenke, die die Gebärden und die Flexion der Glieder ermöglichen. Genau hier, bei der Frage von Gelenk, Artikulation und Gliederung, kommt das Ornament insofern ins Spiel, als seine Struktur außerordentlich gegliedert ist. Mehr noch: Das Ornament ist nichts anderes als »Gegliedertes«; die Gliederung benennt die ornamentale Konsistenz selbst, die Materie, aus der ein Ornament geformt ist. Ein Ornament ist immer Gliederung in Reinzustand. Konkret ist dies ablesbar an der erstaunlichen Tendenz des Ornaments, sich in Zwischenräumen, in Intervallen anzusiedeln, um so eine gewisse Leere zu füllen. Mischstoffe, zur Verknüpfung, Gliederung, zum Zusammenhalten bestimmt wie Gips, Zement, aber auch Knorpel; Füllstoffe, die sich dort ablagern, »wo Platz ist«, in jeder Spalte, jedem Zwischenraum: auf einem Rahmen zum Beispiel, das heißt zwischen dem Werk und dem ihm Äußeren, auf einer Draperie, das heißt zwischen einer Figur oder einem Sujet und seinem Hintergrund. Das Ornament gehört seiner Natur nach zum Weichen, Formbaren, zum sich Faltenden, Biegenden und Nachgebenden, zum leicht Handhabbaren. Grandios hat Schelling von dem "Wunder der Articulation ${ }^{17}$ gesprochen. Dies ist nicht bloß als funktionale Charakteristik aufzufassen, vielmehr liegt darin die eigentliche Essenz des Ornamentalen. Unter ontologischen Gesichtspunkten ist das Ornament weich, und deshalb mag es so schwierig sein, nicht nur darüber zu sprechen- die Wörter präferieren immer die Festigkeit harter Konzepte -, sondern auch dessen Geschichte zu schreiben - der historische Diskurs präferiert immer solide, wohlbestätigte Periodisierungen. Was heißt das anderes, als dass das Ornament differentiell, auf der Basis eines differenzierten Funktionsmodus arbeitet, nicht in einem System, sondern innerhalb eines "Diastemas «? ${ }^{18}$ Die Gliederung, das Gelenk als Fundament des Ornaments zu postulieren heißt, es auf einer Linie der Abzweigung zu gründen. Zur Natur des Ornaments gehört die Gabelung, das Sich-Teilen, Sich-Spalten: natürlich im Raum und in die verschiedenen Richtungen, aber auch in Formen, Gattungen, Reiche, selbst Materialien. Sich verändern und entwickeln heißt in bezug auf das Ornament immer: sich transformieren. Betrachten wir zum Beispiel den Sockel des Silberkreuzes der Opera de Duomo (Abb. 74), wo ein menschlicher Torso, dem Flügel und Haare wachsen, sich zu zwei Löwentatzen und einem Schwanz hin verzweigt, auf dem Akanthusblätter sprießen, die ihrerseits sich einrollen, um in einem großen Kohlblatt zu erblühen ...

Diese wenigen theoretischen Voraussetzungen mögen empfänglicher machen für die Logik der Verzierung, der die Gebärden-Ästhetik von Pollaiuolo unterliegt. Die Verzierung bezeichnet den konkreten, aktualen Modus des Zusammentreffens der beiden Serien. In einer ersten Bedeutung als Figur des Übersteigerten und Hochgezüchteten. Von den Gestikulationen des Herkules bis zu den manierierten Gebärden Davids haben wir es dabei mit Personen zu tun, »die übertreiben«. Der abgespreizte kleine Finger wirkt wie ein Auswuchs des Körpers. Doch eine derartige 
Auffassung der Verzierung ist noch negativ, insofern sie das Ornament zu etwas Zusätzlichem, einem hinzugefügten Motiv macht und damit seine morphologische Positivität übergeht. Hervorgehoben werden müßte vielmehr die Dimension des Floralen und Pflanzlichen, die im Begriff der Verzierung transportiert wird. In den Bildern Pollaiuolos findet in der Tat ein sonderbares gestisches Erblühen statt; Gesten, Gebärden erblühen und entfalten sich um die Körper herum, und ihre Variation ist selbst als eine Art Blütenlese zu verstehen.

Unterstrichen werden muß die erstaunliche Nähe zwischen der Art und Weise, wie sich die Gebärden bei Pollaiuolo entfalten, und dem griechischen oder römischen Rankenornament, zumeist Akanthusblättern. Dabei denken wir nicht nur an die einer solchen Ornamentierung zugrunde liegenden Formen des Einrollens, Wellens, Kräuselns: eine Logik der Rückwendung zu sich, spiralenförmige Motive, Kurven und Gegenkurven usw. (Abb. 66, 72). Wir möchten darin vor allem das Wirken einer trennenden Kraft sehen, die die Rankenornamente sich ständig in sich teilen lässt und Wachstum durch Abzweigung erzeugt. Was treibt denn diesen »abgespreizten«, d.h. von einer Linie der Hand und des Körpers sich trennenden kleinen Finger an, wenn nicht diese ornamentale Entwicklung, die Querwege eröffnet? Man muss sich klarmachen, dass zwischen dem kostbaren Brokat des hl. Eustachius und der Krümmung seiner Hand (Abb. 68) eine seltsame Keimung stattfindet, als könnte die Gebärde über ihre organische Form hinaus sprießen. Dabei fallen einem natürlich die Chimären auf den antikisierenden Grotesken ein (Abb. 71), ein Menschenkörper mit einer Garbe Akanthusblättern, ein Kopf mit Flügeln, Laubwerk, Goldschmiedearbeiten ... Ein einziges Wuchern und Sprießen. Aber auch an die vom gotischen Stil bevorzugten Chimären ist hier zu denken. Der Unterschied ist nur graduell, nicht substantiell zwischen dem Mienenspiel eines Pollaiuolonischen Gesichts und einem phantasmagorischen gotischen Kopf, der gerade durch das ihn in seinem organischen Aufbau Entstellende geschaffen wird: dem Aufblühen sich kräuselnder Kohlblätter oder der Wucherung von Akanthusblättern (Abb. 75). 
Abb. 75

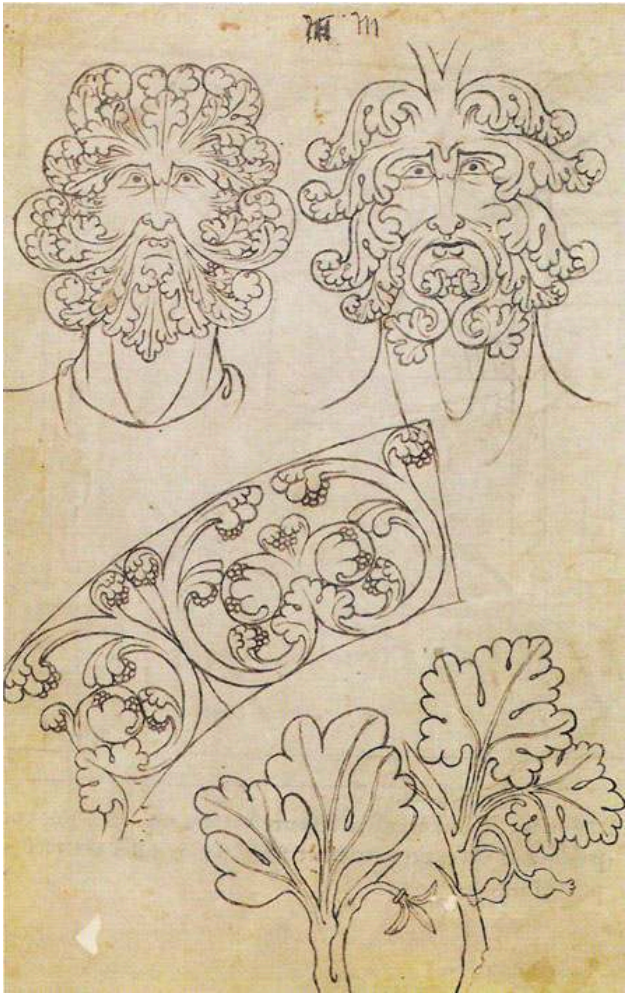

Villard de Honnecourt: Blätterköpfe und Zeichnung von Ornamenten, 13. Jh.

(c) BNF

Der Grund dafür ist, dass die Verzierung eine ganz besondere Vorliebe für Grenzen und Spitzen hat: sie ist ein Phänomen des Rands, der Einfassung. An den Ecken und Winkeln der Fenster, Mauern und Zinnen kräuseln und rollen sich die gotischen Kohlblätter ein. Die Handbewegung konfrontiert nun den Maler zwangsläufig mit der ganz konkreten Frage nach den Enden des Körpers, seinen Extremitäten. Wie in der Malerei einen Körper, ein Glied enden lassen? Mit den Bildern Pollaiuolos, und speziell der Eigenart des abgespreizten kleinen Fingers, gewinnt die Frage einen ganz anderen Status. Denn »es erblüht « immer an den Extremitäten der von Pollaiuolo gemalten Körper, an einer Hand, einem Finger, am Umriss des Körpers. Zu verhindern, dass eine Linie, eine Figur, ein Körper endet, indem sie mehr wie eine Schwelle, wie ein Beginn wirkt und weniger wie der Endpunkt der Linie: darin bestünde also die Wirksamkeit der Verzierung. Das als Verzierung ins Auge gefaßte mimische oder "manische« Merkmal bezeichnet nie einen Schlußpunkt, vielmehr den virtuellen Ausgangspunkt einer unvorhersehbaren Entwicklung; er signalisiert ein unwahrscheinliches Knospen des Körpers, die Kraft eines virtuellen Auftakts, eine Gabelung. 


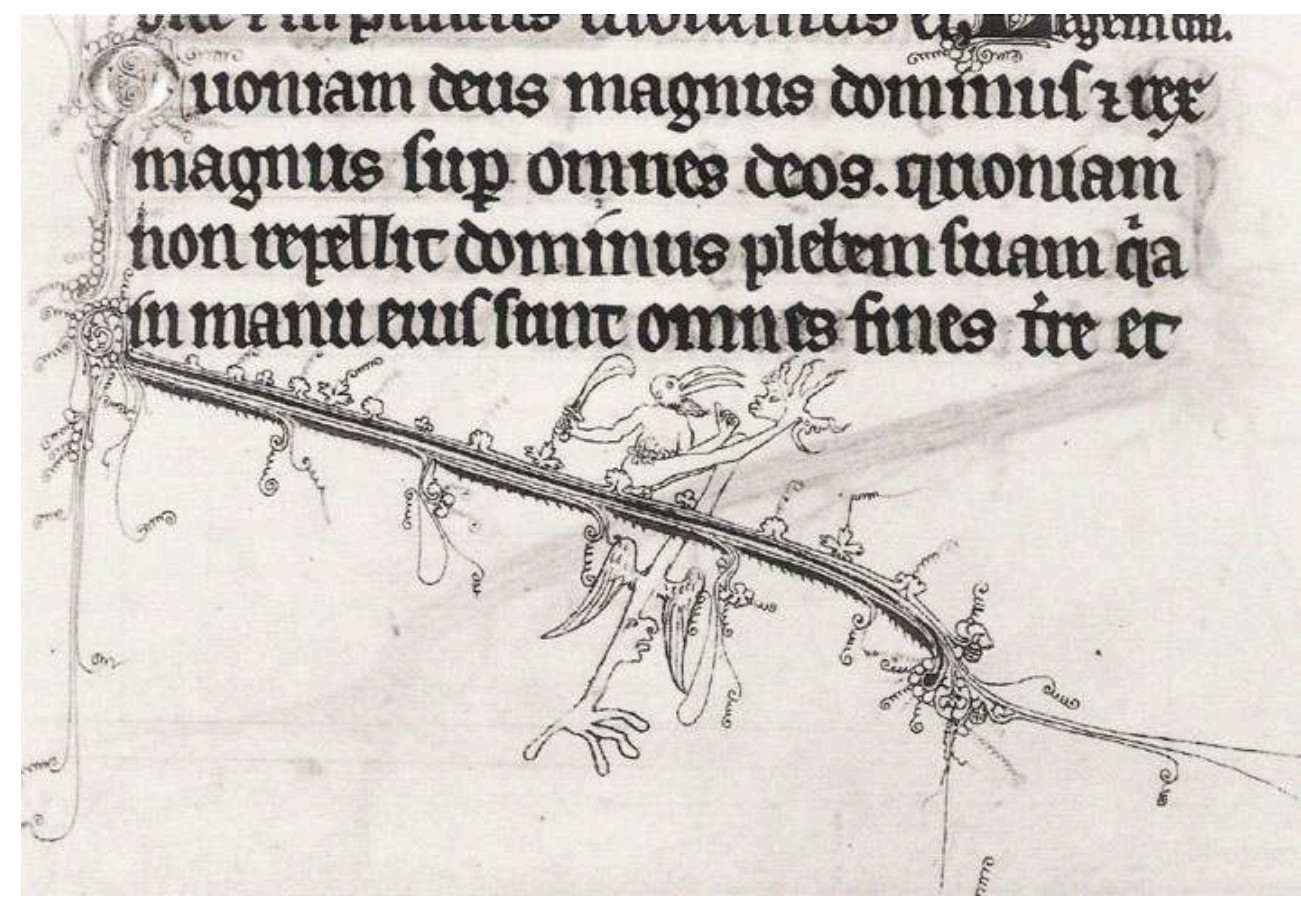

Mittelalterlicher anonymer Künstler: Stundenbuch von Baltimore, Ausschnitt, »gotische Verzierungen« 14. Jh.

Photo (c) The Walters Art Museum, Baltimore

Somit bestünde eine tiefgreifende Affinität zwischen dieser Kraft eines Auftakts, wie sie in den Bildern Pollaiuolos zu finden ist, und dem Wirken jener "Bilder an den Rändern«, mit denen die gotische Buchmalerei die Textseiten gleichsam aufreißt (Abb. 76). Michael Camille hat die enge Beziehung zwischen Rand, Grenze, Spitze und der phantasmagorischen, ja grotesken Entwicklung der gotischen Linie sehr gut nachvollzogen. ${ }^{19}$ Es sind immer die Öffnungen des Textes, sowohl semiologisch (aus Anlaß von Wortspielen) als auch graphologisch (aus Anlaß von Buchstaben mit Unterlängen - z.B. p, q-), an denen die Linien mitgerissen werden und eine Fülle weiterer Linien, Linienstümpfe, Stecklinge, Verschnörkelungen, und andere Figuren entstehen lassen, halb Tier, halb Mensch, die immer Bewegungen des Absetzens und Verzweigens beschreiben. Auf Seiten des sogenannten Stundenbuchs der Marguerite

\footnotetext{
»bilden üppige Verzierungen einen spinnwebartigen Code, der eine Art Schriftimitat zu sein scheint. Bunt durcheinander sprießen Elemente hervor, Linienenden machen Schlenker, hinter Schnörkeln rennen Kaninchen hervor, aus Löchern im Pergament tauchen Hände auf, um quer über die Seite Fangen zu spielen. $\ll^{20}$
}

Es ist offensichtlich, dass Pollaiuolos Ästhetik der Gebärden in enger Verbindung steht zu einer Ästhetik der Linie - wohlverstanden: einer Ästhetik der Linie, die wider alle Vasarinischen Historiographie mitnichten eine Ästhetik des Disegno ist, da das Zeichnen dieser Linie ein Vorhaben beendet, wohingegen die ornamentale Linie Pollaiuolos wie eine Fluchtlinie funktioniert. Wir zögern nicht, den Pollaiuolonischen Linienverlauf als einen gotischen $\mathrm{zu}$ bezeichnen. Zum einen, weil in der hyper-expressiven, fast grimassierenden Mimik der Figuren und Gesichter das Groteske nie sehr fern ist (siehe den auf dem Boden liegenden Kopf Goliaths in David [Abb. 69] oder die Gesichtszüge der nackten Tänzer [Abb. 66]). Zum anderen aber auch, weil die Körper durch eben diese 
Linie - Linien der Kleider, der Accessoires - ihre festen Umrisse verlieren, die Körper und Gebärden entziehen sich im Linienverlauf. Diese Linien sind nicht einmal mehr gestischer Art, werden vielmehr zu rein ornamentalen, zu wellenförmigen, sich schlängelnden Linien. Das gilt für die hinter einem Tänzer wehenden und verschwindenden Bänder (Abb. 66), und analog zu der sich entfaltenden und öffnenden Gebärde. Das gilt für das Löwenfell, das Herkules bedeckt, und die Arabeske, die der Löwenschwanz beschreibt, in Herkules und die Hydra (Abb. 77). Die ornamentale Dimension dieses Schwanzes liegt weder nur in seiner Eigenschaft als etwas an einen Körper Angesetztes noch in seinem wellenförmigen Verlauf, sondern beruht in seiner einzigartigen Anordnung: gerade indem er deutlich an der Horizontlinie endet, ohne die Landschaft zu berühren, gewinnt er umso mehr den Status eines autonomen dekorativen Motivs. Darüber hinaus repliziert er einer erstaunlichen Menge weiterer wellenförmiger Linien: dem mäandernden Fluß im Hintergrund, den Schlangenlinien, in denen Hälse und Schwanz der Hydra verlaufen; wobei letzterer - dem gleichen Rhythmus gemäß wie eine Hand oder ein kleiner Finger - seinerseits in einer Spirale endet, deren Ornamentalität durch ihren frontalen Charakter noch verstärkt wird. Das Ungeheuer ermöglichte es Pollaiuolo natürlich, seinem Hang zur vagabundierenden Linie freien Lauf zu lassen. Doch sollten wir uns hüten, darin bloß eine durch die Ikonographie vorgegebene Möglichkeit zu sehen. Die ornamentale Linie Pollaiuolos birgt eine Kraft, die sie Körper nicht minder als leblose Gegenstände durchqueren, Gebärden hervorbringen, Körper sich winden lässt. Die Haarpracht Maria Magdalenas wird dementsprechend zur Gelegenheit, ihren Körper zu entflammen, um von ihm aus eine Fülle funkelnder gotischer Linien sich entwickeln zu lassen. Ergrünende, aufflammende Körper. Einst sprach ein Kunsthistoriker sehr richtig in bezug auf Pollaiuolo von sich wiegenden Körpern ${ }^{21}{ }^{21}$ Das Wiegen wäre nichts anderes als ein Winden, ein Einrollen, aber in sich selbst, anders gesagt, eine Bewegung im Stillstand. Wie der Tic, wenn auch auf andere Weise, setzt das Wiegen immer das Verhältnis mindestens zweier Kräfte voraus, einem ausgeglichenen Spiel gemäß freilich, worin keine Seite die Oberhand gewinnt über die andere, worin der expressive Merkmalszug entfliehen will, dies ihm aber - im Unterschied zum Tic - nicht gelingt. Das Wiegen impliziert in Wirklichkeit eine gerade sich vollziehende Gabelung, verweist auf einen Zustand der noch nicht differenzierten körperlichen Bewegung, auf eine im Körper noch arbeitende Gebärde.

Wilhelm Worringer hat in seiner sehr schönen Analyse der gotischen Ästhetik das Pathos dieser ornamentalen Linie angemessen gewürdigt. Es ist dem Kunsthistoriker und -theoretiker gelungen, mit den Begriffen einer Pathetik das intensive, anorganische und abstrakte Leben der gotischen Linie $\mathrm{zu}$ erklären, in deren Beschreibung seltsam dionysische Anklänge zu vernehmen sind: "Unstetigkeit«, »unruhiges Drängen", "Rausch", "Maßlosigkeit«, "erhabene Hysterie«, »Empfindungskrampf «, »Empfindungstaumel «, »krampfartige Steigerung« usw. ${ }^{22}$

Dass das die Linie Pollaiuolos antreibende Pathos jeder Darstellung der Körper vorausgeht, dass diese Linie jenseits des Gegensatzes von organischen und anorganischen Formen operiert, das zeigt sich weiterhin und auf wunderbare Weise an dem, was eine ikonographische Einmaligkeit darzustellen scheint: eine unmögliche Windung, ein ornamentales Delirium. Dasjenige, das sich eines Nagels am Kreuz des bösen Schächers bemächtigt (Abb. 78). Dieses Werk, nicht lokalisiert, soll angeblich ein frühes, wenn nicht das erste Werk sein. ${ }^{23}$ Die bösen Schächer, und dies ist ein 
ikonographischer Tatbestand, haben die schlechte Angewohnheit, an ihrem Kreuz zu gestikulieren. Pollaiuolos böser Schächer entzieht sich dieser Überlieferung nicht, ja übertreibt sie sogar: man schaue sich nur das Pathetische des Schreis an, das natürlich an den des von Herkules erdrückten Antäus verweist. Darin nun aber, dass der Nagel sich umwendet, eine Rückwärtsdrehung vollzieht, so als müsste er immer wieder und endlos in das Fleisch dringen, lässt sich - und dies über die offenbare christliche Bedeutung hinaus (sogar der Nagel des bösen Schächers ist böse) - die Kraft einer abstrakten und transversalen Linie erkennen, die sich in allen Formen einzunisten vermag, einem Mienenspiel, einem Band, einem Akanthusblatt, einem kleinen Finger ...

\section{Das Ornamentale der Pollaiuoloschen Produktion}

Damit drängt sich der Gedanke eines sonderbaren afigurativen Pathos auf, einer ornamentalen Expressivität, zu deren nicht unwesentlichen Vorteilen gehörte, dass sie zur Entkörperlichung und damit zur Desakralisierung des Pathos beiträgt: ein anorganisches Pathos, das nicht mehr auf die bildliche Darstellung des Menschen angewiesen ist, sondern alle Formen durchdringt. Neben dieser anorganischen Pathetik der Gebärden und Gesten ist aber auch ein aformales Pathos hervorzuheben, das nicht mehr nur (figurative oder abstrakte) Formen, sondern darstellerische Prozeduren, Entwicklungsverfahren einsetzt. In ihrem Produktionsmodus, ihrer eigentlichen Funktionsweise, öffnen sich die Pollaiuolonischen Gebärden und Körperhaltungen einer ornamentalen Ordnung. Das Ornamentale »ornamentalisiert«, das hei $\beta \mathrm{t}$, es erscheint zunächst

"als modus operandi, dessen strukturierende Funktion es befähigt, alle Genres zu durchdringen. Natürlich fällt das Ornament im traditionellen Sinn vollgültig unter das Ornamentale, aber nur als ein Sonderfall. [...] Hier sprechen wir im Gegenteil von der Ornamentalisierung des Bildes, wenn ornamentale Werte, die nicht zwangsläufig zu einem Motiv-Repertoire gehören, unmittelbar in die Konstruktion von Figuren eingehen oder darin eingreifen. « $^{24}$

Das Motiv der Hand mit dem abgespreizten kleinen Finger ist nicht nur Motiv aufgrund des Blicks des Kunsthistorikers, der es als solches objektiviert; Motiv ist es vielmehr aufgrund des Prozesses, durch den es zur Form gelangt: eines künstlerischen Prozesses, der es mittels eines ornamentalen Modus zu einem individuellen macht. Das Hauptverfahren Pollaiuolos nun ist die Übertragung. Dazu muß man nur sehen, wie die linke Hand des David (Abb. 69) sein nahezu symmetrisches Pendant in der rechten Hand des hl. Eustachius in der Pala de San Miniato (Abb. 68) findet und dass beide sicherlich durch ein gemeinsames Modell verbunden sind. Doch aufgrund der unterschiedlichen Größenverhältnisse der beiden Werke wäre es vermutlich unzulässig anzunehmen, dass die fragliche Übertragung ein ganz konkretes Verfahren bezeichnete, etwas Handwerkliches, das mehr einem Herstellungsverfahren ähnelte als einem künstlerischen Können. Der Florentiner Künstler ist nun genau dafür bekannt: für all diese Verfahren der quasi mechanischen Wiederholung einer Figur mittels Inversion, Collage, Verschiebung der Perspektive, Achsenverschiebung, Reprise ... Ist es also legitim, Pollaiuolo in diese "pattern book tradition « ${ }^{25}$ einzufügen, so muß doch auch die seine Einzigartigkeit angemessen gewürdigt werden.

Diese erweist sich unbestreitbar mit dem Martyrium des hl. Sebastian aus der Londoner National Gallery (Abb. 79). Man hat darin eine originelle (und nie wiederholte) Lösung »der heiklen Frage der Auflösung der Bewegung" gesehen. Von der 
spiegelsymmetrischen Dublette (Gesicht und Rücken) der zwei ihre Armbrust spannenden Schützen im Vordergrund zu der Dublette im Hintergrund, bestehend aus einem Armbrustschützen und einem Bogenschützen (der eine zu Dreiviertel von links gesehen, der andere zu Dreiviertel von rechts), »die ihre Waffe der Wange nähern und sich konzentrieren, bevor sie ihren Pfeil abschießen«; zur Dublette der Bogenschützen ganz links und ganz rechts im Vordergrund, deren angespannte Gestik den unmittelbar bevorstehenden Schuss signalisiert; das Bild vermittelt »die drei Phasen einer Bewegung, die den Körper von einer angewinkelten Position zu einer Haltung der Spannung und der Streckung führen «. ${ }^{26}$ Unter Hinweis darauf, dass Pollaiuolo ebenfalls Bildhauer war, wurde darin auch das Bemühen gesehen, die Figur in einen tiefen dreidimensionalen Raum einzufügen, der ihr große Plastizität vermittelt. Alle diese Verfahren der Verkehrung, der Achsenverschiebung und der Inversion sollen implizieren, dass die in Bewegung begriffene menschliche Figur unter skulpturalen Begriffen zu denken wäre und, mit der Vorstellung eines virtuell freistehenden Körpers spielen. ${ }^{27}$ Richtig ist, dass bestimmte florentinische Künstler aus der 2. Hälfte des Quattrocento (wir denken insbesondere an Verrocchio) mit realen Abgüssen aus Gips oder Erde umzugehen wußten und diese je nach den von den verschiedenen $\mathrm{zu}$ malenden Werken gebotenen anatomischen und gestischen Möglichkeiten integrierten.

Aber ist diese sonderbare Choreographie nicht zunächst einmal das Werk einer phantastischen ornamentalen Logik von Stellungen? Was unterscheidet denn ein ornamentales pattern oder Motiv von einer bloßen Figur oder Form, wenn nicht der Tatbestand, dass das pattern für sich, in einem geschlossenen Kreislauf, als Sujet, nicht existieren kann (außer in einem Sammelband oder einem "Wörterbuch des Ornaments", das die ornamentale Funktionsweise des Ornaments gerade verfehlt)? Umgekehrt existiert das pattern lediglich unter dem Gesichtspunkt seines Gebrauchswerts, insofern es auf etwas - ein Werk, einen materiellen Träger usw. bezogen, damit verknüpft, verbunden wird: eine Logik des parergon, des »Beiwerks«, worin das Ornament nur Bedeutung hat, insoweit es auf das Werk (ergon) bezogen, ihm beigeordnet (par-) wird. Doch diese Sicht des Ornaments, letztlich noch ganz traditionell und vom Idealismus getränkt (da auf Kant und in Wirklichkeit auf Platon zurückgehend, insofern sie auf der Trennung Werk-Essenz vs. Schein-Ornament gründet ${ }^{28}$, verfehlt möglicherweise das Wesentliche. Denn es gilt der Erkenntnis gerecht zu werden, dass ein Ornament von sich selbst ausgeht, auf sich selbst aufbaut, dass es sich nicht in Differenz zu ... (etwas von ihm Unterschiedenem) positioniert, dass es vielmehr in sich selbst differiert, dass es sich als solches differenziert. Das genau macht Das Martyrium des hl. Sebastian sichtbar. Das Ornamentale liegt hier in der spezifischen Art und Weise, in der die Gesten und Stellungen sich aus sich selbst zusammenfügen, sich erzeugen: ein einziges abstraktes Wuchern, das die Körper in ihren Bewegungen gliedert, zusammenfügt. Manifest entsteht dieser Eindruck von Selbst-Erzeugung, von rhythmischer Zirkularität, in der die Figuren erfassenden RundBewegung. Geschuldet ist dieser Reigen von Bogenschützen aber weniger der zirkulären Anordnung der Körper als dem Effekt einer inneren Gliederung der Stellungen, dem Effekt eines gestischen Kontinuums. Ein synkopischer Rhythmus, der den langen Takt der Bogenschützen links und rechts im Vordergrund antreibt, wo die Replik der Stellungen momentan unterbrochen werden muß durch den doppelten kurzen Takt der beiden Armbrustschützen im Zentrum. Eine Reprise, transponiert in den Bogenschützen rechts im Mittelgrund. Dann schließlich Unterbrechung im Armbrustschützen links im Mittelgrund. Man könnte aber auch anderen 
Rhythmusverläufen folgen als den von der traditionellen Bildbetrachtung vorgesehenen: man könnte z.B. vom Armbrustschützen links im Vordergrund ausgehen, der sich in einen Bogenschützen verwandeln würde, um wieder Armbrustschütze zu werden, aber entgegengesetzt zum ersten, dann Bogenschütze, der wiederum dem ersten Bogenschützen entgegengesetzt ist, dann nochmals Bogenschütze, aber diesmal umgekehrt zum ersten Bogenschützen, um schließlich bei einer Position des Armbrustschützen zu enden, aber umgekehrt zur Ausgangsposition. Diese freie Entwicklung ist nicht nur auf Gesten und Stellungen beschränkt. Die ornamentale Rhythmik verläuft auch über die Farben, Stoffe und Bekleidungen: etwa das Blau der Tunika des Bogenschützen links, das sich invers wiederfindet im Revers der Tunika und der Beinkleider des Bogenschützen rechts, Beinkleider, die durch ihre Rotfärbung wiederum auf den Armbrustschützen links (Oberkleid und Strumpfhose) und auf das Revers der Tunika des Bogenschützen im Mittelgrund verweisen. Dieser repliziert wiederum seiner Nebenfigur links durch Ähnlichkeit in Form, Sitz und Farbe (weiß) der Tunika; dieser nacktbeinige Armbrustschütze verweist selbst wiederum auf den nahezu nackten Armbrustschützen im Vordergrund rechts. Schließlich ist auch die Wellenbewegung der Farbe kaum übersehbar, die die vier Stoffgürtel der Personen im Vordergrund durchzieht und miteinander verbindet.

Abb. 80

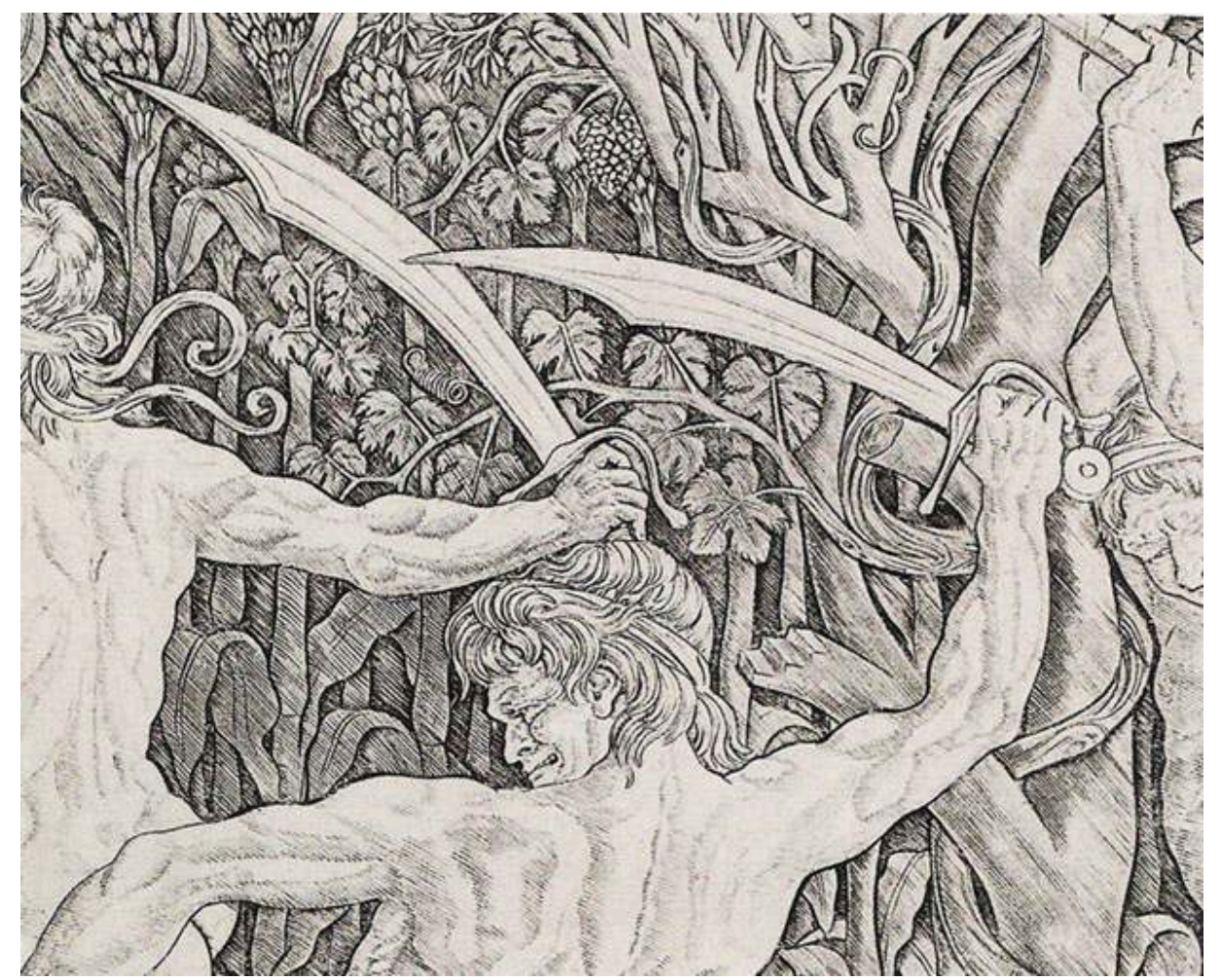

Antonio Pollaiuolo: Nackte Kämpfer, Ausschnitt, ca. 1470.

(c) Ashmolean Museum, University of Oxford

Ein Grundmerkmal der Bilder Pollaiuolos liegt darin, dass sich deren Motive aus sich selbst komponieren, sie die freie ornamentale Bewegung hervorbringen. Dies impliziert, dass die menschliche Gestalt nicht als darzustellende organische Form behandelt werden darf, sondern als ein Ensemble zu entwickelnder abstrakter Motive, die 
sich kraft einer wesentlichen Plastizität aus sich selbst heraus komponieren: einer Plastizität, die jene Motive leicht handhabbar, nach Gutdünken verschiebbar, disponibel macht im Doppelsinn steter Verfügbarkeit und der Fähigkeit, sich je nach formalen und ikonographischen Umständen verteilen zu können bzw. anordnen zu lassen. Diese Plastizität hervorzukehren hat mithin nur Sinn, wenn man begreift, dass der Produktionsmodus dieser Plastizität, ihre »Produktionsgenese«, paradoxerweise auf strikter Zweidimensionalität beruht: plane Oberfläche, Blatt Papier, Muster bzw. Schablone, Karton, die zerschnitten oder zerlegt und in alle Richtungen hin angeordnet werden können und deren planer Charakter eben die Hauptbedingung für ihre Verfügbarkeit darstellt. Unter diesen Umständen kann der mächtige Frontalcharakter der Pollaiuoloschen Bilder nicht überraschen. Ein charakteristisches Merkmal der Kunst Pollaiuolos ist die Disposition seiner Figuren vor weiträumigen und minuziös ausgemalten Landschaftspanoramen (Abb. 18, 24, 42, 54 usw.); dies zeichnet die florentinische Kunst der zweiten Hälfte des Quattrocento in einzigartiger Weise aus und weist damit natürlich einen Bezug zur flämischen Malerei jener Zeit auf. ${ }^{29}$ Wie ist von hier aus das Desinteresse für den Hintergrund zu erklären, von dem andere Werke zu zeugen scheinen? Einmal ist der Hintergrund völlig geschlossen (Abb. 7, 80), ein anderes Mal monochrom gehalten (Abb. 81). In Wirklichkeit besteht gar kein Widerspruch; man muß nur die für Pollaiuolo typische kompositorische Logik in ihrer Besonderheit erfassen. Diese Logik ist nicht die einer räumlichen Konstruktion des pikturalen Raums (mittels Perspektive, Architektur), sondern einer Logik der Gebärden und Stellungen. Die Gebärden komponieren den pikturalen Raum, ordnen, hierarchisieren, gliedern ihn. Das Landschaftspanorama trägt zu dieser Logik insofern bei, als es, aus großer Entfernung betrachtet, einen relativ unbestimmten, verschwommenen Hintergrund bildet, eine wenig differenzierte weitläufige Fläche, von der sich die Figuren nur um so klarer abheben und die Gebärden ganz deutlich in Erscheinung treten. Pollaiuolos technische Sorgfalt (augenfällig in der durch den spezifischen Einsatz der Ölfarbe bewirkten Helligkeit und Durchsichtigkeit der Luft) und seine beflissene Landschaftsschilderung haben ausschließlich den Sinn, den Hintergrund hinsichtlich der vom Bild erzählten Historie kontingent werden zu lassen und mithin den zentralen, frontalen Platz der sich bewegenden Figuren zu verstärken. Die Landschaft erscheint erst, wenn der Blick über die Bildfläche schweift, das heißt, wenn er die Figuren aus den Augen verliert. Häufig stehen diese übrigens auf einer Art Erhöhung oder Felsvorsprung und dominieren damit noch mehr den Hintergrund (Abb. 82, 83): die Figur greift dann auf den Himmel über, der einen umso idealeren Hintergrund abgibt, als er noch gleichförmiger ist als die Landschaft: eine bloße blaue Fläche. Pollaiuolos Bilder sind der nördlich der Alpen verbreiteten Teppichkunst vielleicht insofern verwandt, als in beiden Fällen der Hintergrund wie ein ungegliederter Block, eine undifferenzierte plane Fläche, eine Stoffläche behandelt wird. Diese Fläche kann durchaus kunstvoll bearbeitet sein, wie etwa der Hintergrund bei den beiden Nackten Kämpfern (Abb. 6, 7), zugemalt durch eine dichte Vegetation, deren Motive ein Kontinuum darstellen, was ihre Flächigkeit nur noch stärker hervorstreicht. 


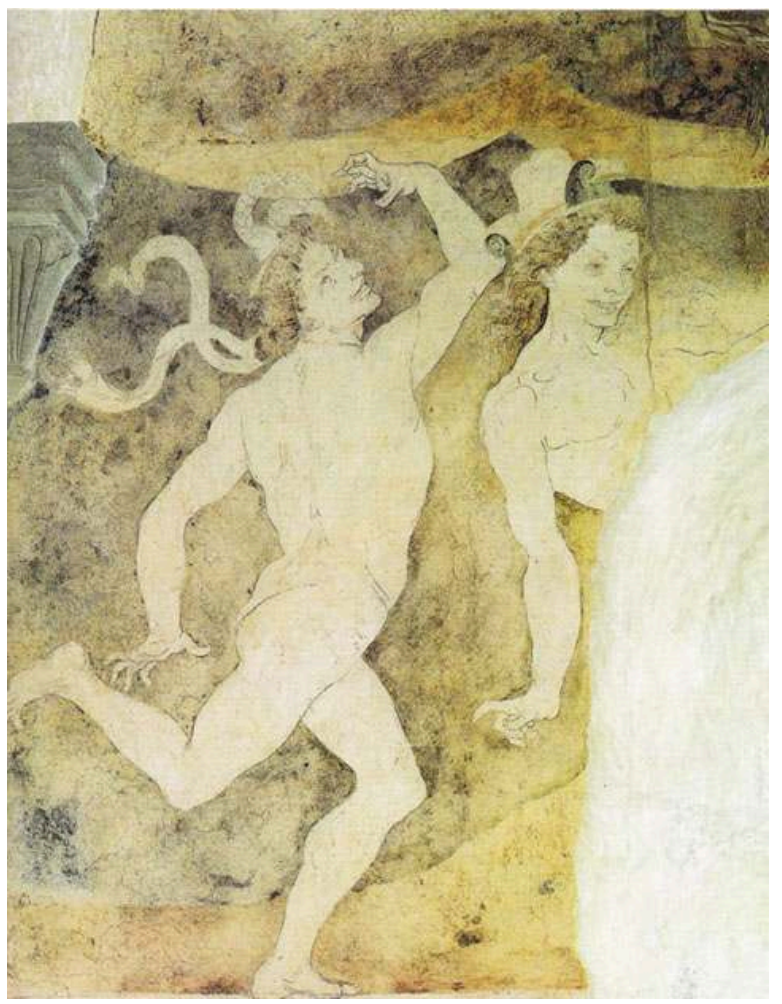

Antonio Pollaiuolo: Nackte Tänzer, Ausschnitt vom linken Teil, 1470-1480.

Diese Logik des Körper-Pattern und des kontinuierlichen Hintergrunds bildet das vorhersehbare Korrelat einer Ästhetik der Gebärde. Wie das? Weil lediglich hochdifferenzierte Stellungen und allein eine plastische Gestik in der Lage sind, den Figuren den Charakter der Einzigartigkeit zu vermitteln. Die Individualisierung dieser Figuren erfolgt nicht durch ihre Einschreibung in einen fiktiven Raum oder auf einen lokalen Hintergrund, der ihnen einen präzisen Ort, eine präzise Stelle zuwiese; diese Figuren unterscheiden sich nicht anhand einer Position in einem Tiefenraum, sondern durch ihre Haltungen und Gebärden an der Oberfläche des Gemäldes. Bei Pollaiuolo ist der pikturale Raum nicht durch eine (perspektivische, architekturale) Tiefe geordnet, sondern bildet sich auf der planen Fläche, entsprechend einem Distributionsgesetz der Gebärden, einem Verteilungsprinzip der Stellungen. Genau diese in besonderer Weise gestische Diskontinuität läßt auf der Oberfläche des Gemäldes eine Kontinuität entstehen, freilich eine durch den Rhythmus der Motive und deren ornamentale Entwicklung geschaffene transversale Kontinuität.

\section{Das abstrakte Pathos Pollaiuolos}

Durch ihren ureigenen Stil bringen uns die Bilder Pollaiuolos zu einer Neubetrachtung dessen, was es unter dem Begriff der Pathosformeln zu sehen und zu denken gibt. Zunächst einmal ist festzuhalten, dass diese Pathosformeln sich mitnichten auf ein Wechselspiel archetypischer Formeln zurückführen lassen, die die Künstler - im vorliegenden Fall Pollaiuolo - je nach Gutdünken wiederverwenden würden. Sinn haben sie lediglich als durch die einzigartige Arbeit der Bilder stetig geschaffene: jedes Bild formuliert auf seine Weise das ihm eigene »Pathos«, erfindet sein eigenes System 
der Gebärden und Stellungen neu. Keine gestische Formel steht im vorhinein fest. Doch mehr noch und tiefer gehend: die Vorstellung einer Gebärden-Formel selbst wird durch die Bilder Pollaiuolos zunichte gemacht, die Vorstellung, dass die Malerei in Gestalt von Figuren, körperlicher, gestischer und posturaler Schemata eine Intensität, einen Wunschstrom in sich sammelt, verdichtet. Mit anderen Worten, die kritische Kraft der Bilder Pollaiuolos besteht im Aufweis, dass jede Vorstellung von "Pathos « nur dann sinnhaft ist, wenn sie jenseits oder diesseits der Darstellung gedacht wird. Hinter der bombastischen, spektakulären Pathetik der Bilder Pollaiuolos gärt eine andere Art "Pathos", sicherlich feiner, unsichtbarer, weniger evident. Uns scheint, dass der Manierismus der Figuren Pollaiuolos eine Art ornamentale Pathetik ins Werk setzt, das heißt mit einem rein pikturalen Element vermischt und komponiert, eine Pathetik, die den Ort dieser einfachen isolierten Figuren überflutet und überfließen läßt und darin die gesamte Malerei mit sich reißt.

\section{BIBLIOGRAPHIE}

Angelini, A., »Considerazioni sull'atticità giovanile di Antonio Pollaiolo `horafo $\mathrm{e}$ >maestro di disegno« in: Prospettiva, 44, 1986, S. 16-26.

Binswanger, L., Drei Formen mißglückten Daseins. Verstiegenheit, Verschrobenheit, Manieriertheit, Tübingen, Max Niemeyer, 1956.

Bonne, J.-C., »De l'ornement dans l'art médiéval ( $\mathrm{VII}^{\mathrm{e}}$-XII ${ }^{\mathrm{e}}$ siècle). Le modèle insulaire«, in: Baschet, J. / Schmitt, J.-C. (Hg.), L'Image. Fonctions et usages des images dans l'Occident médiéval, Paris, Léopard d'Or, 1996 [coll. Cahiers du Léopard d'Or, 5]

Camille, M., Image on the edge: the margins of mediaval art, London, Reaktion Books, 1992.

Carboni, M., L'Ornementale. Tra arte e decorazione, Mailand, Jaca Book, 2000.

Cecchi, A., Il disegno fiorentino del tempo di Laurenzo il Magnifico, Florenz, Silvana, 1992.

Dacos, N., La Découverte de la Domus Aurea et la formation des grotesques à la Renaissance, LondonLeiden, The Warburg Institute, 1969.

Dalli Regoli, G., »Guisto risarcimento per Piero Pollaiuolo, con juicio«, in: Criticà d'arte, 23-24, 2004, S. 49-60.

Dalli Regoli, G., Il gesto e la mano. Convenzione e invenzione nel linguaggio figurativo fra Medievo e Rinascimento, Florenz, Olschki, 2000.

Deleuze, G. / Guattari, F., Kapitalismus und Schizophrenie. Tausend Plateaus, aus dem Französischen übersetzt von Gabriele Ricke und Ronald Vouillié, Berlin, Merve, 1992.

Deleuze, G., Das Bewegungs-Bild: Kino I, übersetzt von Ulrich Christians und Ulrike Bokelmann, Frankfurt/M., Suhrkamp, 1989.

Derrida, J., Die Wahrheit der Malerei, aus dem Französischen von Michael Wetzel, Wien, Passagen Verlag, 1992. 
Didi-Huberman, G., Erfindung der Hysterie. Die photographische Klinik von Jean-Martin Charcot, aus dem Französischen übersetzt und mit einem Nachwort von Silvia Henke, Martin Stingelin und Hubert Thüring, München, Fink, 1997.

Fusco, L., »The use of sculptural models by painters in fifteenth century Italy«, in: The Art Bulletin, LXIV, 1982, S. 175-194.

Galli, A., »Risarcimento di Piero del Pollaiuolo«, in: Prospettiva, 109, 2003, S. 27-588.

Laneyrie-Dagen, N., L'Invention du corps: la représentation de l'homme du Moyen Âge à la fin du XIX siècle, Paris, Flammarion, 1997, Neuauflage 2006.

Mesnil, J., »Botticelli, les Pollaiuolo et Verrocchio«, in: Revista d'arte, 3, 1895.

Morel, P., Les Grotesques, Paris, Flammarion, 1997.

Morelli, G. (alias Ivan Lermolieff), Die Galerien Borghese und Doria Panfili in Rom, Leipzig, Brockhaus, 1890.

Panofsky, E. »Dürers Stellung zur Antike«, in: ders., Sinn und Deutung in der bildenden Kunst, Köln, DuMont, 1978.

Panofsky, E. Die altniederländische Malerei. Ihr Ursprung und Wesen, übers. und hg. von Jochen Sander und Stephan Kemperdick, Bd. 1, Köln, Dumont, 2006.

Ragghianti, C. L. / Dalli Regoli, G., Firenze 1470-1480. Disegni dal modello. Pollaiolo, Leonardo, Botticello, Fillipino, Universität von Pisa, Pisa, 1975.

Schelling, F. W. J., »Die Weltalter«, in: ders., Ausgewählte Werke: Schriften von 1813-1830, Darmstadt, Wissenschaftliche Buchgesellschaft, 1968, 1-150.

Vasari, Lebensläufe der berühmtesten Maler, Bildhauer und Architekten, Übersetzung aus dem Italienischen von T. Fein, Zürich, Manesse, 1974.

Warburg, A. »Der Eintritt des antikisierenden Idealstils in die Malerei der Frührenaissance«, Gesammelte Schriften, Erste Abteilung, Bd. I, 1, Berlin, Akademie Verlag, 1998, (= Reprint von Aby Warburg., Die Erneuerung der heidnischen Antike. Kulturwissenschaftliche Beiträge zur Geschichte der europäischen Renaissance, 1932), S. 173-176.

Warburg, A., »Dürer und die italienische Antike«, in: ders., Gesammelte Schriften, Erste Abteilung, Bd. I, 2, Berlin, Akademie Verlag, 1998, 443-450.

Warburg, A., „Sandro Botticellis `Geburt der Venus` und `Frühling«. Eine Untersuchung über die Vorstellungen von der Antike in der italienischen Frührennaissance«, in: ders., Gesammelte Schriften, Erste Abteilung, Bd. I, 1, Berlin, Akademie Verlag, 1998, 1-60.

Worringer, W., Formprobleme der Gotik, München, Piper, 4. Aufl. 1918.

Wright, A., »Dimensionnal tension in the work of Antonio Pollaiuolo«, in: Curvie, S. / Motture, P. (Hg.), The Sculptural Object, 1400-1700, Cambridge, Scolar Press, 1997, S. 65-86.

\section{NOTES}

1. Aby Warburg, "Der Eintritt des antikisierenden Idealstils in die Malerei der Frührenaissance«, in: ders., Gesammelte Schriften, Erste Abteilung, Bd. I, 1, Berlin, Akademie Verlag, 1998, S. 173-176 (= Reprint von Aby Warburg, Die Erneuerung der heidnischen Antike. Kulturwissenschaftliche Beiträge zur Geschichte der europäischen Renaissance, 1932). Das in diesem wie in den vorhergehenden Kapiteln erkennbare ständige Zaudern zwischen der Bezeichnung »die Gebrüder Pollaiuolo« und 
dem Eigennamen »Pollaiuolo« ist beabsichtigt. In letzter Zeit sind mehrere Versuche unternommen worden, um festzustellen, was jedem der Brüder zuzuschreiben ist: danach wären die Skulpturen und die Kupferstiche mehr das Werk von Antonio; die Gemälde (aber nicht alle) stammten von Piero. Diese Aufteilung ist jedoch mitnichten überzeugend. Aufgrund der großen stilistischen Nähe der beiden Künstler werden wir denn auch gezwungen sein, sie in einer theoretischen Einheit aufgehen zu lassen. Zu diesen Fragen, vgl. A. Galli, »Risarcimento di Piero del Pollaiuolo«, in: Prospettiva, 109, 2003, S. 27-588, und G. Dalli Regoli, "Giusto risarcimento per Piero Pollaiuolo, con juicio? «, in: Criticà d'arte, 23-24, 2004, S. 49-60.

2. Wir übernehmen den Ausdruck von Georges Didi-Huberman aus Erfindung der Hysterie. Die photographische Klinik von Jean-Martin Charcot, aus dem Französischen übersetzt und mit einem Nachwort von Silvia Henke, Martin Stingelin und Hubert Thüring, München, Fink, 1997, 1. Teil.

3. A. Warburg, "Dürer und die italienische Antike«, in: ders., Gesammelte Schriften, Erste Abteilung, Bd. I, 2, Berlin, Akademie Verlag, 1998., S. 447; vgl. auch E. Panofsky, »Dürers Stellung zur Antike«, in: ders., Sinn und Deutung in der bildenden Kunst, Köln, DuMont, 1978, S. 278 f.

4. Carlo Ludovico Ragghianti hat auf die zentrale Stellung Pollaiuolos bei der mit einer gestischen Thematik oder Handhabung [manutention] in Zusammenhang stehenden Etablierung von Hand-»Stilemen« hingewiesen: vgl. C. L. Ragghianti / G. Dalli Regoli, Firenze 1470-1480. Disegni dal modello. Pollaiolo, Leonardo, Botticello, Fillipino, Pisa, Universität von Pisa, 1975, S. 19.

5. Ludwig Binswanger, Drei Formen mißglückten Daseins. Verstiegenheit, Verschrobenheit, Manieriertheit, Tübingen, Max Niemeyer, 1956, S. 119, 128.

6. Vgl. G. Morelli (alias Ivan Lermolieff), Die Galerien Borghese und Doria Panfili in Rom, Leipzig, Brockhaus, 1890, S. 97.

7. Vgl. z.B. Dalli Regoli, Il gesto e la mano. Convenzione e invenzione nel linguaggio figurativo fra Medievo e Rinascimento, Florenz, Olschki, 2000, S. $47 \mathrm{f}$.

8. Denken wir an Gilles Deleuze und seine Aussage zum "Gesicht mit starkem Ausdrucksgehalt" in: ders., Das Bewegungs-Bild: Kino I, übersetzt von Ulrich Christians und Ulrike Bokelmann, Frankfurt/M., Suhrkamp, 1989, S. 126: »Tatsächlich befinden wir uns immer dann vor einem Gesicht mit starkem Ausdrucksgehalt, wenn die Gesichtszüge sich vom Umriß freimachen, auf eigene Rechnung arbeiten und eine autonome, einer Grenze zustrebende oder eine Schwelle überschreitende Serie bilden [...]«.

9. Gilles Deleuze / Félix Guattari, Kapitalismus und Schizophrenie. Tausend Plateaus, aus dem Französischen übersetzt von Gabriele Ricke und Ronald Vouillié, Berlin, Merve, 1992, S. 258.

10. Vasari, Lebensläufe der berühmtesten Maler, Bildhauer und Architekten, Übersetzung aus dem Italienischen von T.Fein, Zürich, Manesse, 1974, S. 263 (Hervorhebung von B.P.) Zur kontroversen Frage um Pollaiuolo als Anatom, siehe B. Schulz, Art and Anatomy in Renaissance Italy, Ann Arbor, UMI Research Press, 1985, S. 51-59; L Fusco, The Nude as Protagonist: Pollaiuolo's Figural Style Explicated by Leonardo's Studies of Static Anatomy, Movement and Functional Anatomy, Dissertation, New York University, 1978 (Widerlegung der Hypothese).

11. A. Warburg, »Sandro Botticellis `Geburt der Venus` und `Frühling«. Eine Untersuchung über die Vorstellungen von der Antike in der italienischen Frührennaissance«, in: ders., Gesammelte Schriften, Erste Abteilung, Bd. I, 1, Berlin, Akademie Verlag, 1998, S. 54.

12. Vasari (1974), [Passage in der deutschen Übersetzung nicht enthalten, A.d.Ü.].

13. Was voraussetzen würde, dass die Werkchronologie genauestens bekannt wäre, was nicht der Fall ist.

14. Vgl. die Notiz von A. Cecchi im Katalog Il disegno fiorentino del tempo di Laurenzo il Magnifico, Florenz, Silvana, 1992, S. 249 f., der »sopravivenza di tali forme in oggetti di questo tipo per tutto il Quattrocento fino alle soglie del secolo sequento« zur Kenntnis nimmt.

15. Vgl. unter anderem A. Angelini, »Considerazioni sull'atticità giovanile di Antonio Pollaiolo shorafor e ımaestro di disegno«", in: Prospettiva, 44, 1986, S. 16-26. 
16. Vgl. N. Dacos, La Découverte de la Domus Aurea et la formation des grotesques à la Renaissance, hg. von J. Brill, London-Leiden, The Warburg Institute, 1969, insbesondere S. 57-77 über die Entstehungsperiode der Grotesken in der 2. Hälfte des Quattrocento. Bereits in der Vorrede, S. VII, vermerkt der Autor zu Recht: »Daß die Entdeckung der Höhlenmalerei ab 1480 ihnen eine große Verbreitung sicherte, lag daran, dass der entsprechende Geschmack daran bereits vorbereitet war: Die Künstler hatten aus der Periode der Gotik das Interesse für das Phantastische und Monströse geerbt, und sie konnten diese Elemente bereits von beiden Seiten einer Zentralachse aufteilen. Die Entdeckung der Grotesken begünstigte somit lediglich eine bereits bestehende Präokkupation, deren wesentliche Elemente herauszuschälen nützlich war.« Über die Grotesken im 16. Jahrhundert, vgl. P. Morel, Les Grotesques, Paris, Flammarion, 1997.

17. Vgl. F. W. J. Schelling, „Die Weltalter«, in: ders., Ausgewählte Werke: Schriften von 1813-1830, Darmstadt, Wissenschaftliche Buchgesellschaft, 1968, S. 133.

18. Diese Bemerkungen verdanken M. Carboni, L'Ornementale. Tra arte e decorazione, Mailand, Jaca Book, 2000, (bes. S. 18, 23, 172, 173 ff.) viele Anregungen.

19. M. Camille, Image on the edge: the margins of mediaval art, London, Reaktion Books, 1992, S. 50.

20. Camille (1992), S. 50.

21. Vgl. J. Mesnil, »Botticelli, les Pollaiuolo et Verrocchio«, Revista d'arte, 3, 1895, S. 11.

22. Vgl. W. Worringer, Formprobleme der Gotik, München, Piper, ${ }^{4} 1918$, S. 50 f., 71, 116.

23. Vgl. Angelini (1986).

24. J.-C. Bonne, "De l'ornement dans l'art médiéval ( $\mathrm{VII}^{\mathrm{e}}-\mathrm{XII}^{\mathrm{e}}$ siècle). Le modèle insulaire«, in: Baschet, J. / Schmitt, J.-C. (Hg.), L'Image. Fonctions et usages des images dans l'Occident médiéval, Paris, Léopard d'Or, 1996 [coll. Cahiers du Léopard d'Or, 5], S. 213.

25. Vgl. L. Fusco, »The use of sculptural models by painters in fifteenth century Italy«, in: The Art Bulletin, LXIV, 1982, S. 175-194.

26. Analyse und Zitate stammen von N. Laneyrie-Dagen, L'Invention du corps: la représentation de l'homme du Moyen Âge à la fin du XIX siècle, Paris, Flammarion, 1997, Neuauflage 2006, S. $46 \mathrm{ff}$.

27. Vgl. vor allem L. Fusco (1982), und A. Wright, »Dimensionnal tension in the work of Antonio Pollaiuolo«, in: Curvie, S. / Motture, P. (Hg.), The Sculptural Object, 1400-1700, Cambridge, Scolar Press, 1997, S. 65-86.

28. Vgl. die berühmten Analysen von Jacques Derrida in Die Wahrheit der Malerei, übers. von Michael Wetzel, Wien, Passagen Verlag, 1992, S.

29. Hier kommt einem natürlich der berühmte Ausspruch Panofskys in den Sinn: »Jan van Eycks Auge arbeitet als Mikroskop und als Teleskop zugleich« (E. Panofsky, Die altniederländische Malerei. Ihr Ursprung und Wesen, übers. und hg. von Jochen Sander und Stephan Kemperdick, Bd. 1, Köln, Dumont, 2006, S. 181.

\section{INDEX}

Schlüsselwörter : Gebärdensprache, Linie, Motiv des abgespreizten Fingers, Ornament, ornamentale Pathetik, Pathosformel, Verzierung

Mots-clés : fioriture, gestuelle, ligne, motif du petit doigt qui rebique, ornement, pathétique ornemental, pathos formel 


\section{AUTEURS}

\section{BERTRAND PRÉVOST}

Kunsthistoriker und -theoretiker, Dozent an der Universität Paris-I Panthéon-Sorbonne 